\title{
Firm Heterogeneity, New Investment, and Acquisitions
}

\author{
Alan C. Spearot * \\ University of California - Santa Cruz
}

July 21,2011

\begin{abstract}
This paper presents a model of investment in which heterogeneous firms choose between new investment and acquisitions. New investment involves purchasing a new plant for an existing variety. Acquisitions involve purchasing a plant from a selling firm along with that firm's established variety. In equilibrium, I show that the structure of demand matters for investment decisions. Using a variable-elasticity demand system, I show that if varieties within a differentiated industry are imperfect substitutes, mid productivity firms choose to invest. In contrast, I also show that as varieties approach perfect substitutability, high productivity firms choose to invest. For both cases, within the region of investing firms, the most productive choose acquisitions over new investment. In analyzing firm-level data from Compustat, I find evidence that supports these predictions.
\end{abstract}

\section{Introduction}

Mergers and acquisitions (M\&As) are an integral, and often very public, form of industrial reallocation. From the merger of complementary resources to the takeover of inefficient firms, M\&As constantly shape and reshape the landscape of domestic and international commerce. However, despite the attention given to M\&As by firms, authorities, and the public at large, a fact often lost is that new capital investment is far more prominent. Indeed, while rarely a year goes by in which firms do not invest in new capital at some level, over the period 1980-2004, 50\% of North American Industrial firms never engaged in acquisitions. Further, in many years, firms engaged in a very large amount of new investment, often in excess of the largest acquisitions. ${ }^{1}$

*Email: acspearot@gmail.com. Address: Economics Department, 1156 High Street, Santa Cruz, CA, 95064. Tel.: +1 831419 2813. I thank John Asker for helpful comments, along with three anonymous referees. I would also like to thank Jim Anderson, Tor-Erik Bakke, Matilde Bombardini, Menzie Chinn, Federico Díez, Charles Engel, Bruce Hansen, John Kennan, Mina Kim, Phillip McCalman, Douglas Staiger, Robert Staiger for many helpful comments. This paper has benefited from presentations at UC-Davis, UC-Santa Cruz, Boston College, Syracuse, Washington State, SCCIE 2007 and EIIT 2006. All remaining errors are my own.

${ }^{1}$ According to Compustat over the period 1980-2004, while $99 \%$ of firms invest in any given year, the median firm has at least one year in which total investment is roughly 5 times larger than their firm-level median over the period. Further, in section three, I detail how average new investment is in excess of average acquisitions in every year. 
How do firms choose between new investment and acquisitions? Given the abundance of evidence suggesting that firms are heterogeneous (for example, in Bernard, Jenson, Redding, and Schott (2007), and Foster, Haltiwanger, and Syverson (2008)), one potential explanation is that heterogeneous firm characteristics motivate investment decisions, both scale and composition. Indeed, the role of firm-heterogeneity within each industry is likely crucial, where if investments can affect firm-level productivity, firms that are already large and productive in a given industry may have very different incentives to invest or acquire when compared with less productive firms. Further, the role of heterogeneity may differ from industry to industry, and may be crucial in terms of crafting appropriate policy for acquisitions. For example, if large firms in a given industry are more likely to acquire than large firms in other industries, should we conclude that firms in the former are engaging in anti-competitive behavior? Or is there something fundamental related to the demand for the products sold and the way in which the products are produced that yields these differences across industries?

While there exist a few exceptions, most models find that high productivity firms are the most likely to invest. ${ }^{2}$ This includes capital investment and acquisitions (Jovanovic and Rousseau, 2002), process investment (Bustos, 2010), foreign investment (Helpman, Melitz and Yeaple, 2004), and quality investment (Verhoogen, 2008) among others. However, a closer look at the data suggests that the analytical and empirical assumptions in previous models may be missing relevant details. Indeed, in Figure 1, I present (on the left) total firm-level investment (new capital investment and acquisitions) as a function of labor "productivity" (sales per worker), and (on the right) the value share of acquisitions in total investment at the firm level, also as a function of labor productivity. While the figure on the right, where acquisitions are preferred to new investment for high productivity firms, is consistent with a number of models, the figure on the left is not. ${ }^{3}$ In particular, while a linear trend would be positive when regressing total investment on productivity, when allowing for a non-parametric relationship between productivity and investment, we find that middle productivity firms engage in the largest amount of investment when compared with their SIC industry peers in each year.

In this paper, I present a model that explains both of these patterns. In particular, I develop a model in which heterogeneous firms choose between a number of capital investment options after the realization of productivity uncertainty. The key difference between investment types in the model is that while both acquisitions and new investment involve purchasing an additional plant,

\footnotetext{
${ }^{2}$ A notable exception is Nocke and Yeaple (2007), which examines how the acquisition and investment behavior of heterogeneous firms respond to various frictions in serving international markets. In their model, firms may wish to acquire the assets of a foreign firm if they are superior to using their own assets in serving a foreign market. In equilibrium, acquisitions are undertaken by the most productive firms as long as capabilities are transferable across borders. If not, greenfield investment is undertaken by the most productive firms and acquisitions by the least productive.

${ }^{3}$ Along with the previous footnote, Jovanovic and Rousseau(2002) presents a model in which fixed costs for acquisitions and imperfect substitution between acquisitions and new investment yields an equilibrium in which high productivity firms choose a larger share of acquisitions in total investment.
} 
Figure 1: Total Investment and Share of Acquisitions in Investment
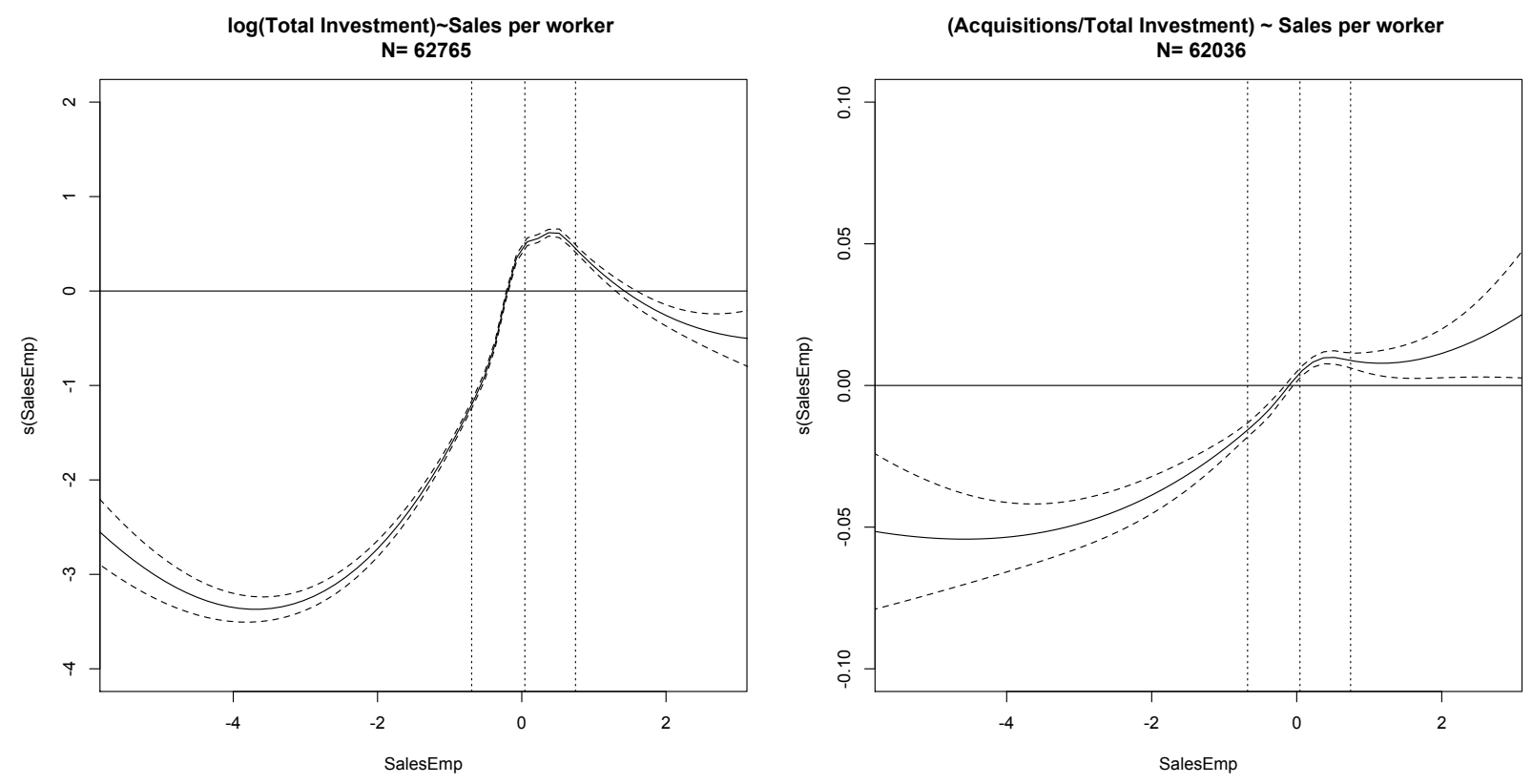

Notes: The left panel illustrates the relative value of investment as a function of SalesEmp (Sales per Worker). The right panel illustrates the value share of acquisitions in total investment as a function of SalesEmp (Sales per Worker). Year, foreign incorporation, and SIC fixed effects are used for each panel. The expected value of s(SalesEmp) is normalized to zero for identification. 90\% Bayesian confidence intervals are provided. The vertical dashed lines represent (from left to right) the 10th, 50th, and 90th percentiles of the productivity measure. Due to outliers (which are included in the estimation) the figures are trimmed at the 0.1 th and 99.9 th percentile of SalesEmp to improve clarity.

an acquisition also provides a firm with an additional established variety of a differentiated product. Within this setup, in conjunction with a variable elasticity demand system, I derive a number of novel predictions related to investment behavior, and the choice between different types of investment. At a more detailed level than in Figure 1, these predictions are confirmed using a 25 year panel of firm-level investment behavior.

The details of the model are fairly simple. Motivated by the lumpy investment behavior described in Doms and Dunne (1998), I assume that all investment occurs in indivisible lumps of capital. This capital is integrated into a constant-returns production function, and is fixed at the time of production. Hence, firms have incentive to invest in capital before production takes place to improve the productivity of more variable factors such as labor.

How do these productivity improvements translate into increased profits? As is well known from the neoclassical literature on investment, in particular Hayashi (1982), the benefits of cost reduction by a single firm are fundamentally governed by the shape and elasticity of the demand 
curve. As such, heterogeneous firms, which may operate at different demand elasticities, may have vastly different incentives to invest. To examine these issues, I utilize a common non-CES demand system (linear) in which varieties are imperfect substitutes and the absolute elasticity of demand is falling with quantity. Hence, high productivity firms tend to earn very little from a productivity improvement through capital investment as they already produce near the point where revenues are maximized. Low productivity firms also earn very little from investment, since any gains are tiny due to their intrinsically low productivity. Instead, I find that middle productivity firms have the highest incentive to invest in additional capital.

The incentives above sufficiently characterize the incentives for new capital investment. However, acquisitions, which involve acquiring capital and an established variety, may be very different. Crucially, the aforementioned revenue constraints, which tend to bind for higher productivity firms, may be alleviated somewhat by adding a variety through an acquisition. Indeed, I show that when an acquisition provides additional capital and management over a closely (though not perfectly) substitutable variety, the incentives for acquisition, while still highest for middle productivity firms, become skewed toward a region of higher productivity. Hence, the relative benefit of an acquisition vis-a-vis new investment increases with productivity. Overall, I show that there exists an equilibrium of the model in which all investment behavior occurs in a middle region of productivity, with the most productive of firms in this region choosing acquisitions over new investment.

To evaluate the effects of substitution across varieties (both acquired and endowed), I examine how the incentives for new investment and acquisitions change with the component of the demand curve that governs product differentiation. Crucially, when consumers do not love variety, all varieties within the differentiated industry are perfect substitutes, and firms act like price takers. Critically, although price-taking behavior may imply that firms are small, the flat demand curve functionally provides firms an unbounded market in which to benefit from both types of capital investment. Hence, as the model approaches this polar case, the incentives for new investment and acquisitions become more skewed toward higher productivity firms. However, the relative incentives between new investment and acquisitions remain qualitatively similar. Overall, the model predicts that different industry types - as measured by total product differentiation within each industry exhibit qualitatively different investment incentives.

I test the predictions of the model using the Compustat North American Industrial database. As in Figure 1, and motivated by the non-monotonic nature of the predictions from the theoretical model, I use non-parametric techniques to estimate the relationship between productivity and investment behavior. Empirically, I find that firms in a middle range of productivity engage in the largest amount of investment, whether it be new investment or acquisitions. This result is robust over a number of different measures of productivity. However, when looking at the relative choice between the two, I find that higher productivity firms choose a larger share of acquisitions in total investment. 
To evaluate the role of product differentiation within industries, I develop a method based on a Hirshman-Herfindahl Index (HHI) over revenues to back-out the implied role of substitution across varieties. While the specifics are presented in the paper, the essential intuition is that, holding other factors constant (number of firms, skew of the productivity distribution), moving toward a price-taking (high substitution) environment tends to amplify the effect of firm heterogeneity on variation in sales. As this tends to disproportionately benefit high productivity (large) firms, this leads to a higher concentration (HHI) in sales. Thus, I categorize industries by their residual HHI after accounting for other factors. Estimating the model using industry subsets based on their implied substitutability, I show that for industries with a high implied substitutability, high productivity firms engage in the largest amount of investment. In contrast, for industries with low implied substitutability, middle productivity firms engage in the largest amount of investment. For both cases, there is a positive relationship between productivity and the value share of acquisitions in total investment. Finally, I show that for acquisitions, these relationships break down when industries have very few firms in each year (on average), suggesting that incentives may be different when firms face few competitors. ${ }^{4}$

\section{Outline}

The rest of the paper is organized as follows. In section two, I present the basic investment model, detailing the fundamental incentives behind capital investment as a function of productivity, and the difference between acquisitions and new investment. The equilibrium components of the model are relegated to the technical appendix. In section three, I test the equilibrium predictions of section two. In section four, I conclude.

\section{Model}

In this section, I present a simple investment model in which firms of heterogeneous productivity choose between new investment and acquisitions. I adopt simple assumptions to make the point that while new investment and acquisitions share similar characteristics that influence overall investment behavior, the added variety that comes with an acquisition explains the composition of investment. A full industry equilibrium model, which solves for an endogenous acquisition price and proves that an equilibrium exists, is presented in the appendix.

The model in this section starts from the point where a fixed measure of firms, each endowed with an established variety and a lump of capital $k$ that is tooled for their variety, realize their productivity level. It is assumed that the set of established varieties is fixed. That is, lags in research

\footnotetext{
${ }^{4}$ Traditional merger models such as Salant, Switzer and Reynolds, (1983), Deneckre and Davidson (1985), Perry and Porter (1985) and Farrell and Shapiro (1990) may be more relevant for industries in which firms have few competitors.
} 
and development prevent new varieties from being invented as a short to medium term response to productivity shocks. In this sense, the model is understood as one of investment incentives in the short to medium run.

Upon realizing their productivity, firms choose from four options. They may (1) invest in a new plant (lump of capital $k$ ) in their current variety, (2) acquire another firm, which includes that firm's plant and variety, (3) do nothing, or (4) sell their plant and variety to another firm and exit the market. Importantly, while both acquisitions and new investment involve acquiring an additional plant, the difference between the two forms of expansion is that with an acquisition, an additional variety is also acquired. Hence, the goal of this section is to not only examine the absolute incentives of each investment choice as a function of productivity, but to also evaluate how the addition of another variety along with capital affects the relative incentives for acquisitions.

After investment decisions are made, firms produce varieties of a differentiated product for consumers. Active firms are monopolists in their own varieties, though are assumed to be small when facing aggregate industry variables. At this point, any capital accrued is fixed, and firms only procure variable factors.

The model is solved by backward induction, and as such, I will begin by solving the firm's problem from the final stage.

\subsection{Product Market Stage}

\section{Demand}

To allow for a simple framework in which absolute elasticities are falling in quantity and firms can produce multiple varieties, I utilize a simplified version of quadratic preferences from Mayer, Melitz, and Ottaviano (2009) and Dhingra (2010). Precisely, defining $I$ as the set of firms and $\Omega_{i}$ as the set of varieties produced by firm $i$, I assume that tastes of the representative consumer are characterized as follows:

$$
U=x_{0}+A \int_{i \in I} \int_{l \in \Omega_{i}} q_{i, l} d l d i-\frac{1}{2} \lambda \gamma \int_{i \in I}\left(\int_{l \in \Omega_{i}} q_{i, l} d l\right)^{2} d i-\frac{1}{2}(1-\lambda) \gamma \int_{i \in I} \int_{l \in \Omega_{i}}\left(q_{i, l}\right)^{2} d l d i
$$

In (1), consumers balance consumption across a numeraire commodity $\left(x_{0}\right)$ and a differentiated industry indexed over firms $(i)$ and varieties $(l)$. In the latter industry, the degree and composition of product differentiation across these firms and varieties is characterized by $\gamma$ and $\lambda$. Total product differentiation is characterized by $\gamma$, which is assumed to be greater than zero. When $\gamma$ is positive, consumers optimally diversify consumption within the differentiated industry across some combination of firms and varieties. ${ }^{5}$ Further, as $\gamma$ falls, consumers view varieties as more substitutable. The

\footnotetext{
${ }^{5} \gamma$ is essentially a parameter that yields a larger disutility when consumers concentrate consumption within some limited subset of firms and/or varieties.
} 
composition of product differentiation is represented by $\lambda \in[0,1]$, which dictates the importance of differentiation that is specific to firms (eg. Apple vs. Dell) relative to individual varieties (eg. MacBook Pro vs. Latitude). Precisely, as $\lambda$ rises, a larger share of product differentiation is specific to firms, not varieties. Indeed, $\lambda$ will control the degree to which varieties within a firm cannibalize one another. ${ }^{6}$

Assuming that the representative consumer has sufficient income to consume within both the differentiated and numeraire industries, the solution to the consumer's problem yields the following inverse demand function for variety $j$ produced by firm $i$.

$$
p_{i, j}=A-\lambda \gamma \sum_{l \in \Omega_{i}, l \neq j} q_{i, l}-\gamma q_{i, j}
$$

To begin a discussion of (2), first consider $\gamma$, which is the parameter that governs overall product differentiation, and hence, the broad patterns of substitution within the differentiated sector. Conducting comparative statics on $\gamma$ allows us to examine how the level of product differentiation affects consumer and firm decisions while holding the composition of this differentiation constant. Generally, when $\gamma$ rises, products are more differentiated, demand is steeper for a given variety and absolute demand elasticities fall. As $\gamma$ approaches zero, varieties approach perfect substitutability within and across firms, and all firms become price takers.

Next, $\lambda$ represents the share of product differentiation that is derived from the aggregate variety provided by each firm, and is taken as given by firms throughout the analysis. ${ }^{7}$ In particular, adjusting $\lambda$ allows us to examine changes to the source of differentiation while holding total product differentiation constant. For example, when $\lambda$ rises, the consumer focuses attention toward the aggregate variety provided by each firm rather than individual varieties. Indeed, higher $\lambda$ represents a case where demand for each variety within a firm is cannibalized to a larger extent by demand for other varieties within the same firm. At the limits, if $\lambda=1$, varieties within the firm are perfectly substitutable (full cannibalization), but imperfect substitutes outside of the firm. In contrast, $\lambda=0$, varieties within the firm are not any more substitutable than they are outside the firm.

Finally, note that in this model, it may be that a firm only produces one variety, in which case $\sum_{l \in \Omega_{i}, l \neq j} q_{i, l}=0$. In this case, the only component relevant for pricing is total product differentiation, $\gamma$.

\footnotetext{
${ }^{6}$ Nocke and Yeaple (2006) uses a CES demand system to examine mergers for scope, though does not allow for any intra-firm cannibalization through cross-price effects as I do in this manuscript. Instead, they assume that there is an efficiency loss associated with acquiring additional varieties.

${ }^{7}$ Unlike Sweeting (2010), I do not allow firms to choose the location of competing varieties within the firm.
} 


\section{Capital and Costs}

Capital influences firm decisions through the cost function. As originally used in Perry and Porter (1985), I assume the following cost function (which itself originates from a Cobb-Douglas production function) for variety $j$ produced by firm $i$ :

$$
C\left(q_{i, j} \mid \alpha_{i}, v, K_{i, j}\right)=\frac{1}{2} \cdot \frac{q_{i, j}^{2}}{\alpha_{i} K_{i, j}}
$$

In (3), $\alpha_{i}$ is firm-level productivity. Productivity across firms is continuously distributed according to $G(\alpha)$, defined over $\alpha \in(0, \infty)$. Firm-level productivity is transferrable across all holdings of capital, and thus all varieties, within the firm. The variable $K_{i, j}$ represents capital accumulated during the initial stage and investment stage by firm $i$ for variety $j$. Critically, it is held fixed when producing varieties for the product market. $^{8}$

\section{Product Market Profits}

At this stage, I begin to restrict the structure of the model as described in the introduction of this section. Precisely, I assume that a firm produces at most two varieties. Under this assumption, and dropping $i^{\prime} s$ for the remainder of the paper, the maximization problem of a firm with two potential varieties is written as follows:

$$
\pi\left(\alpha, K_{1}, K_{2}\right)=\max _{q_{1}, q_{2}}\left\{\left(A-\gamma q_{1}-\gamma \lambda q_{2}\right) q_{1}+\left(A-\gamma q_{2}-\gamma \lambda q_{1}\right) q_{2}+\frac{1}{2} \frac{q_{1}^{2}}{\alpha K_{1}}+\frac{1}{2} \frac{q_{2}^{2}}{\alpha K_{2}}\right\}
$$

Here, $\alpha$ represents firm-level productivity, and $K_{1}$ and $K_{2}$ are the capital levels associated with varieties 1 and 2, respectively. Again, as variety specific capital is fixed at the time of production, marginal costs for each variety are increasing in quantity.

As written in (1), I assume that firms have no effect on $A$. This implies that firms are small, and that even if they acquire another firm, there is no change in the residual demand for each variety. This is a strong assumption that implies a very strict form of nesting in the consumer's decision (in concert with the assumption of monopolistic competition). ${ }^{9}$ However, the focus of this section is to evaluate how investment incentives change with productivity, and in particular, how the addition of a variety through acquisitions affects the relative incentives for acquisitions vis-a-vis new investment. The assumption of small firms that may add varieties through acquisitions greatly simplifies the presentation of these incentives. I will return to this assumption in the latter part of the empirical section, focusing on industries that are more likely to be oligopolistic.

In the product market stage, there are potentially three types of active firms: those that did

\footnotetext{
${ }^{8}$ Indeed, the fixed nature of capital is why the underlying Cobb-Douglas production function does not yield a constant unit-cost function in this model.

${ }^{9}$ Essentially, this implies that consumers choose firm first, and then from their chosen firm's set of varieties.
} 
nothing in the investment stage, those that invested in their endowed variety, and those that acquired another firm. For those firms that did nothing during the investment stage, they produce subject to their endowed capital level $k$. Adopting the convention that a firm's endowed variety is labeled as variety 1 , we have that $K_{1}=k$, and $K_{2}=0$ for firms that do not invest. Subject to these capital holdings, profits are written as:

$$
\pi(\alpha, k, 0)=\frac{A^{2} \alpha k}{2(2 \gamma \alpha k+1)}
$$

Next, consider a firm that invested in its own variety in the investment stage. For simplicity, assume that the firm has added an additional lump of capital to its current variety. ${ }^{10}$ Hence, $K_{1}=2 k$, and $K_{2}=0$. Subject to these capital holdings, profits are written as:

$$
\pi(\alpha, 2 k, 0)=\frac{A^{2} \alpha k}{(4 \gamma \alpha k+1)}
$$

Finally, consider a firm that has acquired another firm in the investment stage, which includes a lump of capital $k$, and a variety that is attached to it. Hence, $K_{1}=k$, and $K_{2}=k$. Subject to these capital holdings, profits are written as:

$$
\pi(\alpha, k, k)=\frac{A^{2} \alpha k}{(2 \alpha \gamma \lambda k+2 \gamma \alpha k+1)}
$$

The profit functions in (5), (6), and (7) exhibit a number of intuitive features. First, for $\lambda<1$, it is straightforward to show that $\pi(\alpha, k, k)>\pi(\alpha, 2 k, 0)$. Abstracting from the costs of each option that occur in a previous stage, acquiring another firm, which includes a lump of capital $k$ and another variety, is always preferred to investing in a lump of capital in the firm's endowed variety. Intuitively, acquiring another firm provides the benefits of additional capital, without the full reduction in demand elasticity (cannibalization) that would occur by doing so in the firm's current variety. This point is sharpened by noting that when $\lambda<1, \frac{\partial \pi(\alpha, k, k)}{\partial \alpha}>\frac{\partial \pi(\alpha, 2 k, 0)}{\partial \alpha}$ for all $\alpha$. That is, this difference becomes larger when productivity increases. As higher productivity firms operate on a less elastic portion of the demand curve, issues of demand elasticity are more pronounced, and the benefit of an acquisition relative to new investment is enhanced. In a moment, I will fully characterize the profit functions, and differences between them, as a function of $\alpha$.

Finally, note that when $\lambda=1, \pi(\alpha, k, k)=\pi(\alpha, 2 k, 0)$. Here, a firm that acquires operates two identical plants (lumps of capital) that produce perfectly substitutable varieties within the firm. This is a qualitatively identical outcome to when a firm invests in another plant for its endowed variety. That is, given the cost specification in (3), equalizing marginal cost across plants that

\footnotetext{
${ }^{10}$ The technical appendix offers a case in which firms may choose capital in any amount. The fundamental investment incentives do not change qualitatively when firms can by any amount of capital.
} 
produce perfectly substitutable varieties is the same as doubling the size of a firm's existing plant. ${ }^{11}$

I now roll back to the investment stage to further evaluate differences in profits as a function of productivity, along with introducing the fixed costs associated with investment options.

\section{$2.2 \quad$ Investment Stage}

Subject to profits earned in the product market, firms make investment choices in the previous stage. As described in the introduction, firms choose one of four options in the investment stage. This decision can be characterized by the following discrete choice problem:

$$
V(\alpha)=\max \left\{R_{a}-\pi(\alpha, k, 0), 0, \pi(\alpha, 2 k, 0)-\pi(\alpha, k, 0)-F_{I}, \pi(k, k)-\pi(k, 0)-R_{a}\right\}
$$

For reasons which will become clear, I write the profits of each option relative to the "outside option" of doing nothing. In the first entry of (8), the benefit of selling relative to doing nothing is written as $R_{a}-\pi(\alpha, k, 0)$, where $R_{a}$ is the acquisition price that is paid to the selling firm. Next, the benefit of doing nothing relative to itself is zero. In the third entry of (8), the benefit of new investment relative to doing nothing is $\pi(\alpha, 2 k, 0)-\pi(\alpha, k, 0)-F_{I}$, where $F_{I}$ is the fixed cost of investing in a new lump of capital. Finally, $\pi(k, k)-\pi(k, 0)-R_{a}$ represents the benefit of acquisitions relative to doing nothing, where $R_{a}$ is again the price of the acquisition. As written in (8), firms choose the option which maximizes profits at their level of productivity, $\alpha$.

Moving forward, I will first characterize the incentives for acquisitions and new investment as a function of productivity. This will be sufficient to show how the incentives for new investment and acquisitions are consistent with the patterns summarized in Figure 1. The remaining components of the equilibrium acquisition model are relegated to the appendix, where I show that there exist parameter values such that an acquisition equilibrium exists, and that the equilibrium yields acquisition behavior consistent with all elements of Figure 1.

\section{New Investment}

The key to the model is how incentives for each type of investment, which are defined as the profits earned from the investment relative to doing nothing, change with productivity. To begin, focus on the incentive function for new investment, $\Pi_{I}(\alpha)=\pi(\alpha, 2 k, 0)-\pi(\alpha, k, 0)$. These are the additional profits that a firm receives, relative to doing nothing, if it engages in new investment. As a function of model parameters, $\Pi_{I}(\alpha)$ is written as:

$$
\Pi_{I}(\alpha)=\frac{A^{2} \alpha k}{2(4 \gamma \alpha k+1)(2 \gamma \alpha k+1)}
$$

\footnotetext{
${ }^{11}$ This is true for a general Cobb-Douglas production function. This derivation is available upon request.
} 
It is straightforward to show that $\Pi_{I}(\alpha)$ equals zero when $\alpha=0$, and approaches zero when $\alpha \rightarrow \infty$. Indeed, the maximum of $\Pi_{I}(\alpha)$ occurs at $\alpha=\hat{\alpha}_{I} \equiv \frac{\sqrt{2}}{4 \gamma k}$. The intuition for these properties lie at the heart of the demand-cost framework. The least efficient firms are limited by a steep marginal cost schedule. Whether or not they invest, they are still quite unproductive, and the absolute gains from new investment are tiny. The most efficient firms are constrained not by costs, but by the structure of market demand. Specifically, the highest productivity firms operate on a less-elastic portion of the demand curve, which limits the incentive to expand production after purchasing a lump of new capital. Firms in a mid-range of productivity are constrained by neither, and earn relatively high returns from new investment.

To examine how total product differentiation affects investment incentives, note how $\gamma$ affects the productivity level at which $\Pi_{I}(\alpha)$ is maximized. Indeed, as $\gamma$ falls the productivity level at which $\Pi_{I}(\alpha)$ is maximized rises, and in the limit, approaches infinity. As $\gamma$ governs demand elasticities at a given level of quantity, $\gamma$ will have a profound effect on the firms which find new investment profitable. I will return to this point later in this section, and in the empirics.

Finally, note that these results are not specific to the linear demand assumption that is employed throughout the paper. In the technical appendix, using a model of marginal capital purchases and the cost function in (3), I show that the marginal value of added capital is highest for firms in a mid-range of productivity as long as the elasticity of the marginal revenue curve with respect to quantity is finite, negative, and falling sufficiently with higher quantity. This is not satisfied when firms are price takers, or when firms produce subject to standard CES demand. However, this is satisfied by linear demand, and a larger class of demand functions.

\section{Acquisitions}

Next, consider the incentive function for an acquisition, $\Pi_{M}(\alpha)=\pi(k, k)-\pi(k, 0)$. As a function of model parameters:

$$
\Pi_{M}(\alpha)=\frac{A^{2} \alpha k(2 \gamma \alpha k-2 \alpha \gamma \lambda k+1)}{2(2 \gamma \alpha k+2 \alpha \gamma \lambda k+1)(2 \gamma \alpha k+1)}
$$

To begin the analysis of $\Pi_{M}(\alpha)$, note when $\lambda=1$, the two varieties are perfectly substitutable within the firm, and the acquisition incentive function $\Pi_{M}(\alpha)$ simplifies to $\frac{A^{2} \alpha k}{2(4 \gamma \alpha k+1)(2 \gamma \alpha k+1)}$, which is the same incentive function as in $\Pi_{I}(\alpha)$. Hence, when varieties are perfect substitutes within the firm, but imperfect substitutes across firms, those firms in a mid-range of productivity have the highest incentive to acquire another firm.

At the other extreme, when $\lambda=0, \Pi_{M}(\alpha)=\frac{A^{2} \alpha k}{2(2 \gamma \alpha k+1)}=\pi(\alpha, k, 0)$. In this case, varieties are not substitutable within the firm, and acquiring an additional unit of capital simply doubles the profits of holding one lump of capital (no cannibalization of one variety by another variety). Further, for this case, the incentives to acquire another firm are increasing in productivity. 
Figure 2: Investment Incentives - Low and high $\lambda$

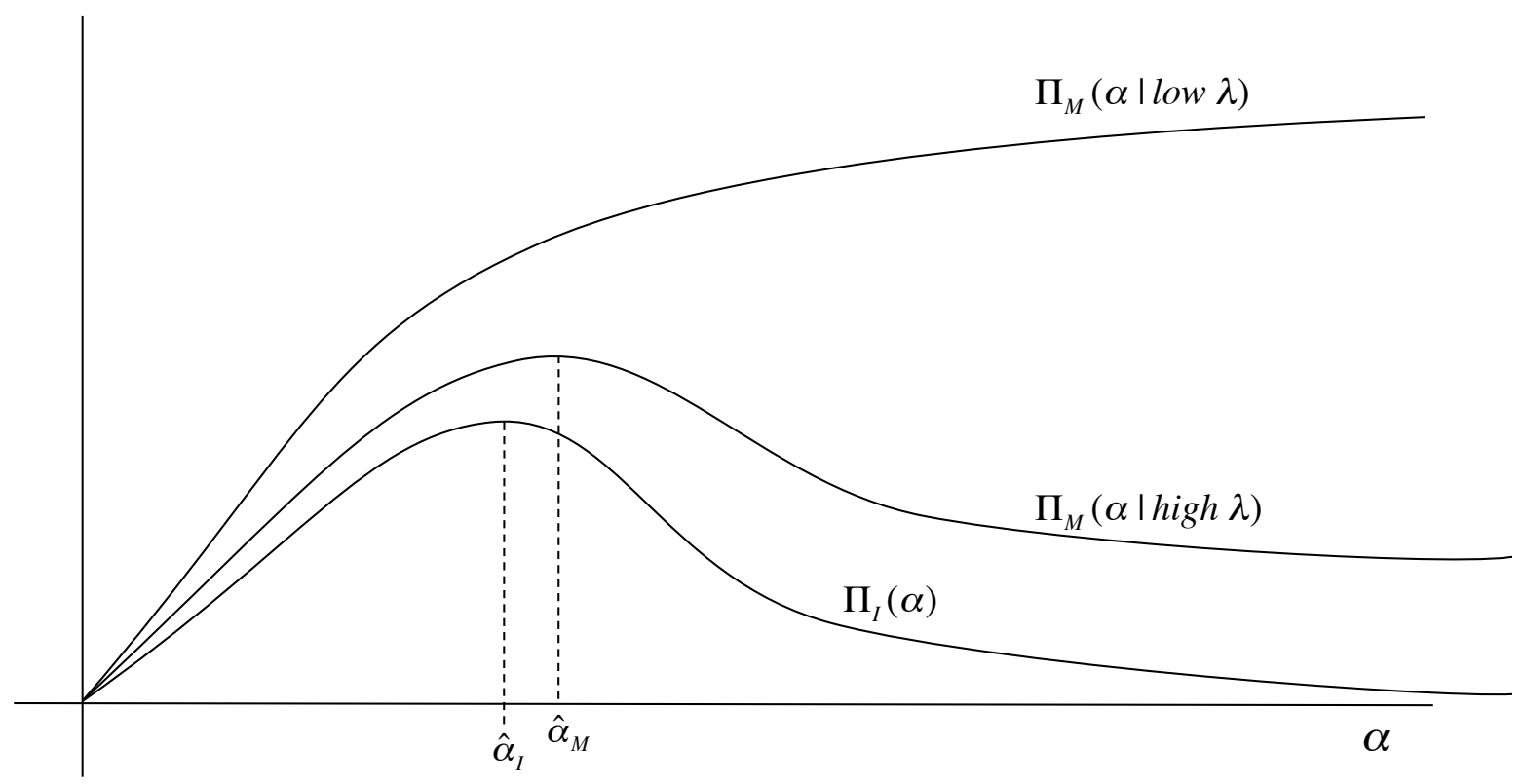

The polar cases of $\lambda$ suggest that higher productivity firms in some cases (and unlike for new investment) will have incentive to acquire another firm. This can be clearly seen by solving for the value of $\alpha$ at which $\Pi_{M}(\alpha)$ is maximized. Precisely, $\Pi_{M}(\alpha)$ is maximized at $\alpha=\hat{\alpha}_{M} \equiv \hat{\alpha}_{I} \frac{(2-\sqrt{2})}{(1+\lambda-\sqrt{2})}$. While the numerator is positive, the denominator is positive only if $\lambda>\sqrt{2}-1$. Overall, this implies that for $\lambda \in(\sqrt{2}-1,1]$, there exists a mid-productivity level such that acquisition incentives are maximized.

To further examine the role of $\lambda$ in characterizing the difference between the incentives for new investment and acquisitions, note that the maximum of $\Pi_{M}(\alpha)$ relative to the maximum of $\Pi_{I}(\alpha)$ can be written as follows:

$$
\frac{\hat{\alpha}_{M}}{\hat{\alpha}_{I}}=\frac{(2-\sqrt{2})}{(1+\lambda-\sqrt{2})}
$$

In (11), $\gamma$ is absent, where only $\lambda$, the share of product differentiation that is attributable to firms, matters for the relative position of $\Pi_{M}(\alpha)$. Hence, when $\hat{\alpha}_{M}$ exists in the range $(0, \infty)$, as $\gamma$ falls toward zero, $\hat{\alpha}_{M}>\hat{\alpha}_{I}$ and both rise toward infinity at the same rate. I will come back to this point in the empirical section of the paper when discussing different types of industries as measured by their total level of product differentiation. I will also discuss the empirical results when there are potentially non-zero correlations between $\gamma$ and $\lambda$ in the data.

Figure 2 details the difference between incentives for new investment and incentives for acquisi- 
tions. As long as $\lambda<1, \Pi_{M}(\alpha)$ is always larger than $\Pi_{I}(\alpha)$. Further, as detailed in Figure 2, and

discussed above, $\frac{\partial \Pi_{M}(\alpha)}{\partial \alpha}>\frac{\partial \Pi_{I}(\alpha)}{\partial \alpha}$ for $\lambda<1$. Hence, the relative advantage of acquisitions over new investment increases with productivity. The intuition for this property is straightforward. When allowing for new investment within a firm's endowed variety, the crucial issue is how improvements to variable factor productivity map into higher sales and profits. When absolute demand elasticities fall with higher quantities, high productivity firms have a relatively difficult time increasing sales after increasing their capital stock. A solution to this issue is to invest in another variety, which given the short-medium run nature of the model, is done so by acquisitions. Hence, high productivity firms have the highest incentive to acquire another firm, both in absolute terms, and relative to new investment.

A few features of Figure 2 worth reinforcing again are that when $\lambda$ is relative high, the incentives for both new investment and acquisitions are highest in a middle range of productivity. However, the relative attractiveness of acquisitions increases with productivity. Both predictions are consistent with the features in Figure 1, and I examine both predictions at a detailed level in the forthcoming empirical section. In particular, I will develop a proxy for $\gamma$ - the measure of total substitutability within the differentiated industry - where the model predicts that incentives for investment of both kinds shift toward higher productivity firms at the same rate as $\gamma$ falls.

For interested readers, the remaining elements of the investment model, including equilibrium components, are presented in the technical appendix. In particular, I account for the different fixed costs of each investment option, and acquisition costs that are endogenous through a market clearing condition for firms. In equilibrium, I show that when $\lambda$ is relatively close to one and $F_{I}$ not too large, all investment occurs in a middle range of productivity, with the more productive firms in this region choosing acquisitions over new investment.

\section{Empirics}

In this section, I test the predictions of the model as they relate to the relationship between productivity and investment behavior, the choice of investment type, and the relationship between product substitutability and investment behavior. To begin the empirical section, I will describe the data, the measure of productivity, and the estimation procedure.

The sample of active firms is constructed using the Compustat North American Industrial database. Within the mergers/investment literature, this database has also been used by Jovanovic and Rousseau (2002), Rhodes-Kropf and Robinson (2008) and Breinlich (2008). The time period of analysis is 1980-2004. The primary sample is constructed using firms from industries with SIC codes less than 4000. These are primarily agricultural, commodity, and manufacturing firms. This will yield a sample of 7,702 firms totaling 62,765 observations.

The primary productivity measure will be sales per worker for firm $i$ in year $t$, which is labeled 
SalesEmp $p_{i, t}$. The motivation for using sales per worker is that it has a structural relationship to $\alpha k$, which is the firm-level measure in the model that predicts investment behavior. I provide a derivation of this relationship in Appendix C. To measure sales per worker, I first construct a naive measure by dividing yearly net sales of firm $i$ in year $t\left(\right.$ Sales $\left._{i, t}\right)$ in millions of dollars (Compustat item 12) by yearly employment in millions of workers (Compustat item 29 divided by 1000). However, two additional steps are taken to yield a measure which is both easily interpretable, and closely applied to the theory. First, I take the natural log of sales per worker to control for outliers which will distort the illustrations required for a non-parametric analysis. Second, the model detailed above describes static investment choices within a given industry. Thus, log sales per worker is demeaned within SIC-year pairs, yielding the final measure, SalesEmp $p_{i, t}$.

I use a simple nonparametric specification to estimate the relationship between productivity and investment activity. The procedure I use is an "additive model", which allows for joint estimation of both parametric and nonparametric components of an empirical specification. Following the procedure in Wood (2007), using the MGCV package for R, I estimate the following model:

$$
\text { Outcome }_{i, t+1}=s\left(\text { SalesEmp }_{i, t}\right)+\vec{\beta}_{\text {Other }} \text { Other }_{i, t}+\epsilon_{i, t}
$$

Equation (12) estimates the relationship between the right-hand side variables in the current period and an outcome at the firm level in the next period. Using this approach prevents an obvious endogeneity problem between the outcome and covariates from the same period. Thus, investment behavior covers the period 1981-2004, and firm and industry covariates cover 1980-2003. In (12), Outcome $_{i, t}$ is some outcome measure for firm $i$ in year $t$. I will focus on four outcomes: $\log$ value of acquisitions (Computstat item 129), log value of new capital investment (Computstat item 30), $\log$ value of total investment (both new investment and acquisitions), and the value share of acquisitions in total investment. ${ }^{12}$ Further, the term Other $_{t, i}$ includes Year, SIC, and foreign incorporation fixed effects (the latter being a dummy variable identifying firms incorporated in Canada).

In (12), $s\left(\right.$ SalesEmp $\left._{i, t}\right)$ represents a smooth function in SalesEmp $p_{i, t}$. For identification purposes, $E\{s()\}=0$, where $s()$ measures the relative effect of its argument. Conveniently, zero will always measure the average value of the outcome after accounting for fixed effects, and thus, evaluating $s()$ and its confidence bands relative to zero will facilitate a hypothesis test of whether predicted investment activity is above or below average. To facilitate relatively quick estimation, $s()$ will be estimated using a penalized cubic-spline regression. This allows for a generally specified smooth fit, along with a penalty in the likelihood function for too much "wiggliness". The optimal degree of smoothing is chosen by a generalized cross-validation procedure.

\footnotetext{
${ }^{12}$ For values of the outcome that are equal to zero, I add $\$ 1$ before taking logs. This is mostly applicable for acquisitions, where roughly $75 \%$ of firms do not acquire in each year. However, the results for acquisitions are qualitatively similar when using a binary outcome variable, and are available upon request. For new investment, rarely a year goes by in which a firm does not invest in new property plants and equipment, and as such, this assumption is largely irrelevant for new investment and total investment.
} 
Figure 3: Descriptive Measures: New Investment, Acquisitions
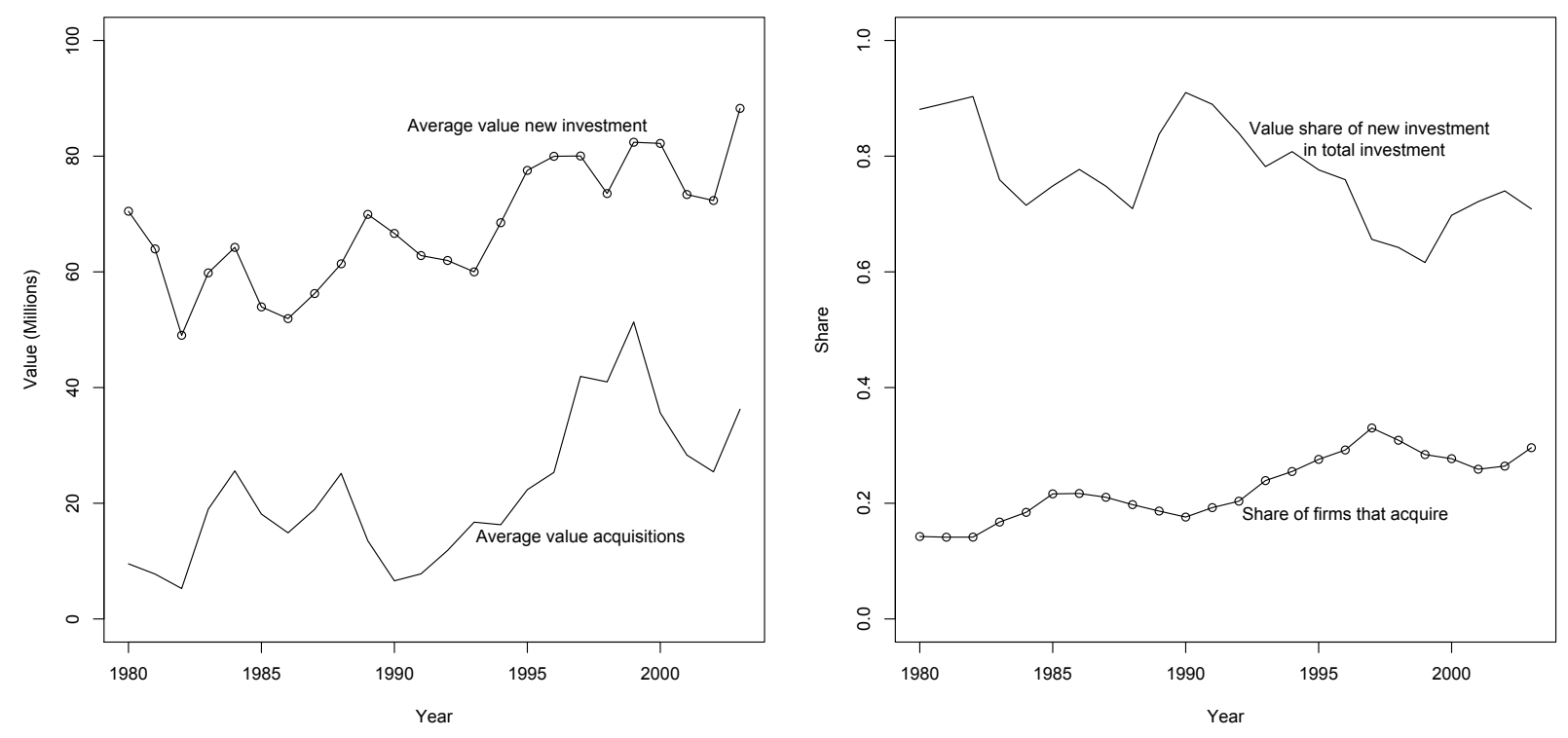

For the baseline results, along with SalesEmp $p_{i, t}$, I will also use a version that corrects for within-firm autocorrelation, and an auxiliary measure of TFP. The latter measure is calculated by collecting the residual after regressing the $\log$ of sales on capital and labor. ${ }^{13}$ Note that, unlike SalesEmp $p_{i, t}, T F P_{i, t}$ is not structurally related to the theory, since Sales is used as the regressand rather than output. However, as it is used in a multitude of productivity studies, I will present results using TFP for comparison with SalesEmp it, $_{\text {. }}$

To get a sense of how investment behavior has evolved over time, Figure 3 presents descriptive measures for average firm-level new investment and acquisitions in each year in the left panel, and the value share of new investment in total investment and the share of firms that acquire for each year in the right panel. In the left panel, we see that investment behavior has increased over time, whether it be acquisitions or new investment. However, new investment behavior appears to be less variable relative to trend, which is not shocking given that new investment includes smaller yearly investments such as machine replacement. In the right panel, we see that acquisition behavior has slowly become more prevalent over time, starting at roughly $20 \%$ in 1980, and increasing to around

${ }^{13}$ Precisely, TFP will be defined as the residual from the following regression:

$$
\begin{aligned}
\log \left(\text { NetSales }_{i, t}\right)= & \beta_{\text {cap }}^{T F P} \log \left(\text { Cap }_{i, t}\right)+\beta_{E m p}^{T F P} \log \left(\text { Emp }_{i, t}\right)+ \\
& \vec{\beta}_{\text {sic }}^{T F P} S I C+\vec{\beta}_{\text {year }}^{T F P} \text { Year }+\beta_{\text {can }}^{T F P} F I N C+\epsilon_{i, t}
\end{aligned}
$$

Here, along with previously defined variables, $C_{a p} p_{i, t}$ is the value of property, plants and equipment (Compustat item 8) 
$30 \%$ after 2000. This can also be seen in the value share of new investment in total investment, which while noisy, appears to be falling over sample period.

\section{Baseline Results}

Using the three productivity measures, the results from estimating equation (12) for the four investment outcomes are presented in Figures 5, 6, and 7. In all three figures, I find significant support for the model. Looking at acquisitions and new investment separately, I show that for each, middle productivity firms tend to engage in more investment relative to their SIC peers in each year. When aggregating all investment together, I find the same result. For all investment types, there exists a range of firms above the 90th percentile of sales per worker for which investment is significantly below average. Finally, within the subset of firms that do invest, as productivity increases, firms choose a larger share of acquisitions in total investment. This result is slightly less impressive for TFP, though it is still the case that the highest productivity firms choose a share of acquisitions in total investment that is significantly above average.

\section{The Role of Substitution}

The strongest support for the model will be in analyzing investment incentives across different industry types in terms of how consumers value product variety. In section two, the parameter $\gamma$, which captured the consumer's total love of variety in the differentiated industry, also governed the degree to which incentives for both acquisitions and new investment were skewed toward high productivity firms. For all values of $\gamma, \alpha_{M}>\alpha_{I}$. However, as $\gamma \rightarrow 0$ while holding $\lambda$ fixed, both $\alpha_{M}$ and $\alpha_{I}$ approached infinity at the same rate. Hence, if I can construct a suitable measure for $\gamma$, I can evaluate the incentives for investment across different industry types. I now will argue that such a measure exists. Then, I will construct subsets of the data according to their implied value of $\gamma$, and estimate (12) for each subset to evaluate whether incentives change across different industry types.

The key to constructing a measure for $\gamma$ is noting that in low $\gamma$ industries, productivity differences will be most apparent in observable sales outcomes. That is, when varieties within the differentiated industry are more substitutable, observed sales heterogeneity should be larger. To capture this idea using a common measure, I will leverage the properties of a Hirschmann-Herfindahl Index (HHI) in

pre-acquisition sales to back-out an implied measure of $\gamma$. To see how this measure works, define the observed HHI over pre-acquisition sales for industry $k$ in year $t$ as follows:

$$
H H I_{k, t}=\frac{\sum_{i \in S_{k, t}} \text { Sales }_{i, t}^{2}}{\left(\sum_{i \in S_{k, t}} \text { Sales }_{i, t}\right)^{2}}
$$

In (14), $S_{k, t}$ is set of varieties in industry $k$ in year $t$, and Sales $_{i, t}$ is the net sales of variety $i$ in year 
$t$. In the appendix, I prove the following relationship between $H H I_{k, t}$ and $\gamma$.

Lemma 1 Holding $S_{k, t}$ fixed, $\frac{\partial H H I_{k, t}}{\partial \gamma}<0$

Proof. See Appendix.

Thus, as $\gamma$ falls to zero and consumers value variety less, productivity differences are enhanced in terms of observed sales concentrations. This causes the HHI to rise. The intuition is subtle, though straightforward. Lower values of $\gamma$ imply that consumers care less about variety and more about the average price of varieties. Hence, consumers shift on the margin away from high-price (low-productivity) varieties to lower price (high productivity) varieties. Overall, concentration of sales increases.

There are a number of other factors that can affect $H H I_{k, t}$. For one, increasing the number of varieties will tend to reduce $H H I_{k, t}$. Also, a productivity distribution which is skewed heavily toward larger firms may increase $H H I_{k, t}$. Further, the set $S_{k, t}$ may be endogenous. Thus, while Lemma 1 is proven rigorously, it is meant to provide an example of how $\gamma$ affects sales concentration within this particular economic environment.

With this in mind, to "recover" gamma, I exploit the residual variation in concentration after regressing $\log \left(H H I_{k, t}\right)$ on $\log \left(N_{k, t}\right)$, the $\log$ of the number of firms in SIC industry $k$ in year $t$, $\log \left(S k e w_{k, t}\right)$, the $\log$ ratio of maximum productivity to median productivity for SIC industry $k$ in year $t$, and $\log \left(\right.$ AvgSalesEmp $\left.p_{k, t}\right)$, which is the log of average sales per worker for SIC industry $i$ in year $t$. The results from doing so are presented below:

$$
\begin{array}{r}
\log \left(H H I_{k, t}\right)=-\underset{(0.0237)}{0.231}-\underset{(0.00691)}{0.5014} \log \left(N_{k, t}\right)+\underset{(0.0105)}{0.0912 \log \left(\text { Skew }_{k, t}\right)}-\underset{(0.00982)}{0.0811} \log \left(\text { AvgSalesEmp }_{k, t}\right) \\
R^{2}=0.562
\end{array}
$$

Here, as expected, more firms leads to a lower value of $H H I_{k, t}$. Further, Skew $w_{k, t}$ has a positive effect on $H H I_{k, t}$. Intuitively, this implies that concentration is high when the most productive firm is more productive relative to the industry median. Finally, AvgSalesEmp $p_{k, t}$ has a negative effect on concentration.

To rank industries in terms of their implied value of $\gamma$, I first collect the residuals from (15), which are at the SIC-year level. Then, I will use two methods to classify industries by their implied value of $\gamma$. First, I will simply group industries into terciles of residuals in each year. Precisely, within each year, those in the lowest tercile of residuals will be labeled as having a "high" relative value of $\gamma$. That is, after accounting for factors that are not directly related to $\gamma$, SICs within each year with relatively low concentration will tend to have a higher implied value of $\gamma$. Similarly, the second tercile of the residuals will be labeled as "mid" values of gamma, and the highest labeled as "low" values of $\gamma$. This approach will be referred to as "Method 1". For a second approach, I take the residuals and take averages over years for each SIC industry. Then, I construct terciles 
as described above using the average residuals for each SIC industry. The crucial difference with above is that I am now restricting tercile assignment to be invariant over time. This approach will be referred to as "Method 2".

Next, I estimate the model over different data subsets defined by the method used to back-out $\gamma$, and their tercile of implied $\gamma$. The results from doing so for acquisitions, new investment and total investment, are presented in Figures 8,9 and 10. Within each Figure, there are six panels with two rows and three columns. "Method 1" is used for the top row of results, and "Method 2" is used for the bottom row of results. Further, implied values of $\gamma$ go from low to high as we move from left to right across columns in each Figure. In Figures 8, 9 and 10, middle productivity firms have the highest incentive to invest only if the implied value of $\gamma$ is relatively high. This is the case when using "Method 1" (allowing for implied $\gamma^{\prime} s$ to change over time), and when using "Method 2" (restricting that implied $\gamma^{\prime} s$ are time invariant). Precisely, looking at the far right panels in each figure, we see that for high values of $\gamma$, investment of all types is significantly below average for firms above the 90th percentile of sales per worker. In contrast, in the left panels of each figure, where $\gamma$ is relatively low, investment is well above average for high productivity firms. Hence, the implied value of $\gamma$ relates to the qualitative features of investment incentives as the theory predicts.

Next, in Figure 11, I examine the relative incentives between acquisitions and new investment. In contrast with the absolute incentives for acquisitions and new investment, the relative incentives for acquisitions compared with new investment should not change qualitatively with $\gamma$. Regardless of the level of $\gamma$, as productivity increases, firms tend to prefer acquisitions to new investment. The results in Figure 11 are supportive of this prediction. While there are a few hints of non-monotonicity in the estimated non-parametric functions for mid- $\gamma$, in no cases is the acquisition share for the most productive firms significantly different from the highest point of the non-parametric fit. Hence, across different values of $\gamma$, the data support the prediction that as productivity increases, firms tend to prefer acquisitions to new investment.

One criticism of the above analysis is that $\lambda$ is held fixed and close to one. In reality, there may be potential correlations in the relationship between $\gamma$ and $\lambda$ that complicate the discussion of Figure 8. Indeed, in Figure 8, low- $\gamma$ industries display acquisition incentives that are increasing in productivity, and high- $\gamma$ industries display acquisition incentives that are highest in a mid-range of productivity. The only way that these results are inconsistent with the theoretical model in section two is if there is a strong negative relationship between $\gamma$ and $\lambda$ in the data. ${ }^{14}$ In other words, as products become more differentiated, the firm level component of differentiation becomes irrelevant. While there is no way to test this hypothesis without estimating a full demand model, I view this as being unlikely. This would imply that in the most differentiated industries (e.g. motor vehicles or computers), on average, there is a relatively small firm-level component of product differentiation.

\footnotetext{
${ }^{14}$ Precisely, defining $\lambda$ as a function of $\gamma, \frac{\partial \alpha_{M}}{\partial \gamma}>0$ if $\frac{\partial \lambda}{\partial \gamma}<-\frac{1+\lambda-\sqrt{2}}{\gamma}$. That is, the maximum of the incentive function rises with product differentiation if there is a strong negative correlation between $\lambda$ and $\gamma$.
} 
Another potential criticism of the above approach, especially in-light of using residual $H H I_{k, t}$ to back-out values of $\gamma$, is that I am still not controlling properly for industries that have relatively few firms. That is, the framework of monopolistic competition that is the basis for the model in section two may not be suitable for describing investment behavior in oligopolistic industries. Of particular concern is that it may be appropriate for large firms in these industries to internalize the effects of their investment decisions on industry level measures. To see this, first consider how large firms might affect industry aggregates through new investment. By investing in new capital, they add to the total industry capital stock, increasing average labor productivity, but without directly reducing the number of firms. This would tend to make the industry more competitive, not less competitive, and shift down the residual demand for all varieties, $A$. Hence, market concentration does not increase the incentives for new investment for high productivity firms. In contrast, consider a large firm that acquires another large firm, where the remaining firms are either few or small fringe firms. Within this concentrated setting, $A$ may rise after an acquisition since there will be one large firm in the market rather than two. Hence, larger (productive) firms, which may have paltry acquisition incentives when $A$ is fixed, now may have additional incentives for an acquisition when they acquire their primary competitor in a concentrated market. Hence, in concentrated settings and unlike new investment, we could expect to see acquisition incentives where high productivity firms are more likely to acquire independent of $\gamma$.

To evaluate how the empirical incentives for investment change when industries contain relatively few firms, I use the following procedure along with implied $\gamma$ 's from "Method 1". First, I calculate the average number of firms listed in Compustat for each SIC industry in each year. Then, I classify SIC industries as either above median or below median in terms of the average number of firms listed per year. The median across SIC industries is approximately 7 firms listed per year. Then, I estimate the model using subsets of the data based on their terciles of implied gamma and relative number of firms per year.

The results from doing so are illustrated in Figures 12, 13, 14 and 15. Here, we see that the results for new investment and total investment in Figures 13 and 14 do not depend on the relative value of $N$ in each year. Specifically, for low implied $\gamma$, new investment is significantly larger than average for high productivity firms. For higher implied $\gamma$, new investment is above average for middle productivity firms and below average for high productivity firms.

In contrast, when we look at acquisition behavior as a function of productivity in Figure 12, we see that for industries with an above median number of firms in each year, the results conform with the previous results presented in Figure 8. However, for industries with relatively few firms in each year, we see that empirical acquisition incentives are quite different. In particular, for the two lowest terciles of implied $\gamma$, we see that acquisition incentives are always largest for high productivity firms. For the highest tercile of implied $\gamma$, there is no significant relationship between acquisition behavior and productivity. As discussed above, these results suggest that large firms 
in industries with relatively few competitors are accounting for their effect on industry aggregates through investment, in particular, acquisitions.

\section{Longer Investment Windows}

In (12), investment behavior is regressed on observables from the previous period. It is likely, however, that corporate expansion occurs in periods longer than one year. In this subsection, I evaluate the model over a longer window of investment activity.

As I have a 25 year panel of firm-level behavior, I split up the panel in 5 year increments. Within each, I measure productivity in the first year (eg. 1980) and investment behavior over the next four years (eg. 1981-1984). Productivity is measured exactly as described above (for the first year in each five year window). For investment behavior, I measure the log value of acquisitions, the log value of new investment, the log value of total investment, and the value share of acquisitions in total investment over the four year window. Given these variable definitions, I drop firms within a five year window that do not report data over all five years. Thus, along with evaluating investment behavior over a longer period, it should be understood that these results are interpretable only for continuing firms.

The results from running (12) using wider investment windows over different subsets of implied $\gamma$

are presented in Figures 16, 17, 18, and 19. In the first three, we see that despite the longer windows of acquisition activity, the results support the model. That is, when $\gamma$ is relatively low, acquisition and investment behavior is skewed toward higher productivity firms. When $\gamma$ is relatively high, investment is highest in a middle region of productivity. In the fourth, Figure 19, we see that as productivity increases, high productivity firms are more likely to choose acquisitions over investment. Indeed, the longer investment windows seem to smooth out some of the non-monotonicity for mid$\gamma$ panels in Figure 11. Overall, I find that using a longer investment window does not have a qualitative effect on investment behavior.

\section{Conclusion}

This paper explores the relationship between industry-level characteristics and firm-level investment behavior. In particular, I show that a critical factor influencing firm-level investment behavior is the degree to which consumers love variety. When varieties are imperfect substitutes and firm-level demand elasticities fall with output, mid productivity firms have the largest incentive to invest. However, when varieties are close to perfect substitutes, high productivity firms have the largest incentive to invest. For both cases, within the region of firms that do invest, high productivity firms tend to prefer acquisitions. In evaluating 25 years of data from Compustat, I find sharp evidence for all predictions of the model.

Future work is bound to focus on two areas: matching in the acquisition market, and foreign 
acquisitions. With regard to the former, part of the simplicity of the model is based on the assumption of a common price of acquired capital within each industry. In reality, acquisition prices are bargained after potential matches are identified, and there is likely a tremendous amount of uncertainty within each potential acquisition. With regard to the latter, a large share of FDI involves the transfer of ownership across borders. While a companion paper (Spearot, 2011) extends the acquisition components of the above model to a setting with multiple countries and trade costs, more work is needed to precisely address the welfare effects of foreign acquisitions vis-a-vis other forms of market-entry. 


\section{References}

[1] Bernard, Andrew, Bradford Jenson, Stephen Redding, and Peter Schott (2007), "Firms in International Trade", Journal of Economic Perspectives, Vol. 21-3, pp. 105-130.

[2] Breinlich, Holger (2008), "Trade Liberalization and Industrial Restructuring through Mergers and Acquisitions," forthcoming Journal of International Economics Vol. 76-2

[3] Compustat Users Guide, The McGraw-Hill Companies, Inc., 2003

[4] Denececkre, Ray and Carl Davidson (1985), "Incentives to Form Coalitions with Bertrand Competition", Rand Journal of Economics, vol. 16-4 pp. 473-486.

[5] Dhingra, Swati (2010), "Trading away wide brands for cheap brands", mimeo London School of Economics.

[6] Doms, Mark, and Timothy Dunne (1998), "Capital Adjustment Patterns in Manufacturing Plants", Review of Economic Dynamics, vol 1, pp. 409-429.

[7] Farrell, Joseph and Carl Shapiro (1990), "Horizontal Mergers: An Equilibrium Analysis", American Economic Review, vol. 80-1, pp. 107-126.

[8] Foster, Lucia, John Haltiwanger, and Chad Syverson (2008), "Reallocation, Firm Turnover, and Efficiency: Selection on Productivity or Profitability?", American Economic Review, Vol. 98-1, pp. 394-425.

[9] Hayashi, Fumio (1982), "Tobin's Marginal q and Average q: A neoclassical Interpretation", Econometrica, vol. 50, pp. 213-223

[10] Helpman, Elhanan, Marc Melitz and Stephen Yeaple (2004), "Exports versus FDI with heterogeneous firms." American Economic Review, vol 94, 300-316.

[11] Jovanovic, Boyan and Peter Rousseau (2002), "The Q-Theory of Mergers, " American Economic Review, vol. 92, pp. 198-204.

[12] Maksimovic, Vojislav and Gordon Phillips (2001), "The Market for Corporate Assets: Who Engages in Mergers and Asset Sales and Are There Efficiency Gains?", The Journal of Finance, No. 6, pp. 2011-2052.

[13] Mayer, Thierry, Marc J. Melitz and Gianmarco I. P. Ottaviano (2009), "Market size, Competition and the Product Mix of Exporters", mimeo.

[14] Nocke, Volker and Stephen Yeaple (2007), "Cross-Border Mergers and Acquisitions versus Greenfield Foreign Direct Investment: The Role of Firm Heterogeneity", Journal of International Economics, 2007, vol. 72-2, pp. 336-365. 
[15] Nocke, Volker and Stephen Yeaple (2006), "Globalization and Endogenous Firm Scope", mimeo University of Pennsylvania.

[16] Perry, Martin and Robert Porter (1985), "Oligopoly and the Incentive for Horizontal Merger", American Economic Review, vol. 75, pp. 219-227.

[17] Matthew Rhodes-Kropf and David Robinson (2008), "The Market for Mergers and the Boundaries of the Firm", The Journal of Finance, Vol 83-3, pp. 1169-1211.

[18] Salant, Stephen W., Sheldon Switzer and Robert J. Reynolds (1983), "Losses from Horizontal Merger: The Effects of an Exogenous Change in Industry Structure on Cournot-Nash Equilibrium", The Quarterly Journal of Economics, vol. 98, pp. 185-199.

[19] Spearot, Alan C. (2011), "Market Access, Investment, and Heterogeneous Firms", mimeo University of California at Santa Cruz

[20] Sweeting, Andrew (2010), "The effects of mergers on product positioning: evidence from the music radio industry", Rand Journal of Economics, Vol. 41-2, pp. 372-397.

[21] Verhoogen, Eric (2008), "Trade, Quality Upgrading and Wage Inequality in the Mexican Manufacturing Sector", Quarterly Journal of Economics, 123-2, pp. 489-530.

[22] Wood, Simon (2007), "The MGCV Package", www.r-project.org. 


\section{A Technical Appendix}

In this appendix, I fully characterize the equilibrium of a model subject to incentives described in section two. There, I detailed the incentives for acquisitions and new investment in terms of what is earned in the product market. Now, I add in the fixed costs required for each investment type, and derive when a firm of productivity $\alpha$ prefers one type of investment over another. Then, I prove that there exist parameter values such that an equilibrium is unique and supports the behavior detailed in Figure 1.

To characterize the remaining incentives and equilibrium of the model, I will henceforth assume that $\lambda$ is relatively close to one, where the incentives to acquire another firm are highest in a middle range of productivity and $\lim _{\alpha \rightarrow \infty} \Pi_{M}(\alpha)$ is not too high (this will be made precise below).

\section{A.1 Investment Choice}

To characterize the investment choice problem, I will first compare each option in the investment stage to the outside option of doing nothing. Then, I will compare the two expansion options to one another. Finally, I will present the acquisition market clearing condition, which sets the stage for solving the equilibrium of the model.

\section{New investment}

I will now compare new investment $(I)$ to doing nothing $(N)$. To begin, assume that $F_{I}$ is not prohibitively large, where $F_{I}<\max _{\alpha} \Pi_{I}(\alpha) .{ }^{15}$. Defining $\underline{\alpha}_{I}$ and $\bar{\alpha}_{I}$ as the values of $\alpha$ such that $\Pi_{I}(\alpha)=F_{I}$, the following lemma follows directly from the shape of $\Pi_{I}(\alpha)$

Lemma 2 For finite $\gamma$, the choice between doing nothing (N) and investing in new capital (I) as a function of productivity is summarized as follows:

$$
\text { For } \begin{aligned}
& \alpha \in\left[0, \underline{\alpha}_{I}\right], N \succ I \\
& \alpha \in\left(\underline{\alpha}_{I}, \bar{\alpha}_{I}\right), I \succ N \\
& \alpha \in\left[\bar{\alpha}_{I}, \infty\right), N \succ I
\end{aligned}
$$

Proof. Immediate from shape of $\Pi_{I}(\alpha)$.

The intuition for Lemma 2 is as discussed in section two. Firms in a middle range of productivity have the highest incentive to invest in new capital relative to doing nothing given the demand structure detailed in (2). However, this does not imply that middle productivity firms necessarily invest in new capital, since there are other options related to acquisitions and selling. I now discuss these options relative to doing nothing.

\section{Acquisitions}

With the fixed cost $R_{a}$ detailed in (8), firms are indifferent between doing nothing and acquiring another firm when $\Pi_{M}(\alpha)=R_{a}$. Since I assume that $\lambda$ is close to one, if $R_{a}$ is neither trivially small or large (not close to zero or above the maximum of $\Pi_{M}(\alpha)$ ), there will exist two productivity

\footnotetext{
${ }^{15}$ This assumes that investment is not trivially unprofitable for all firms
} 
cutoffs, $\underline{\alpha}_{M}$ and $\bar{\alpha}_{M}$, such that $\Pi_{M}(\alpha)=R_{a}$. The following lemma summarizes the preference conditions over acquisitions and doing nothing around these cutoffs.

Lemma 3 For finite $\gamma$ and $\lambda$ close to 1, the choice between doing nothing ( $N)$ and acquiring another firm (M) as a function of productivity is summarized as follows:

$$
\begin{aligned}
\text { For } & \alpha \in\left[0, \underline{\alpha}_{M}\right], N \succ M \\
& \alpha \in\left(\underline{\alpha}_{M}, \bar{\alpha}_{M}\right), M \succ N \\
& \left.\alpha \in\left[\bar{\alpha}_{M}, \infty\right]\right), N \succ M
\end{aligned}
$$

Proof. Immediate from shape of $\Pi_{M}(\alpha)$.

Thus, when varieties of a product are relatively substitutable with one another within the firm (finite $\gamma, \lambda$ close to 1 ), the data should show similar qualitative incentives for new investment and acquisitions.

\section{New Investment vs Acquisitions}

In Lemmas 2 and 3, I compared each option of expansion, new investment and acquisitions, to the option of doing nothing. I now compare each option of investment to one another. Indeed, firms are indifferent between acquisitions and new investment when $\Pi_{M}(\alpha)-\Pi_{I}(\alpha)=R_{a}-F_{I}$. Since there is no obvious way to characterize $R_{a}-F_{I}$ as being trivially large or small, it is possible that there exists no value of $\alpha$ such that firms are indifferent between acquisitions and new investment. However, if it exists, define this productivity level as $\alpha_{I M}$. The following lemma summarizes preference conditions around this indifference point.

Lemma 4 The preference conditions between $I$ and $M$ are as follows:

- If $R_{a}-F_{I}<0$, then $M \succ I$ for all $\alpha$.

- If $0<R_{a}-F_{I}<\lim _{\alpha \rightarrow \infty} \Pi_{M}(\alpha)$ and $\lambda=1$, then $M \succ I$ if $R_{a} \leq F_{I}$, and $I \succ M$ if $R_{a}>F_{I}$.

- If $0<R_{a}-F_{I}<\lim _{\alpha \rightarrow \infty} \Pi_{M}(\alpha)$ and $\lambda<1$, then the following summarizes the choice between $M$ and $I$ as a function of productivity.

$$
\text { For } \begin{aligned}
& \alpha \in\left[0, \alpha_{I M}\right], I \succ M \\
& \alpha \in\left(\alpha_{I M}, \infty\right), M \succ I
\end{aligned}
$$

- If $R_{a}-F_{I}>\lim _{\alpha \rightarrow \infty} \Pi_{M}(\alpha)$, then $I \succ M$ for all $\alpha$.

Proof. Straighforward from the property that $\pi(\alpha, k, k) \geq \pi(\alpha, 2 k, 0)$ and $\frac{\partial \pi(\alpha, k, k)}{\partial \alpha}>\frac{\partial \pi(\alpha, 2 k, 0)}{\partial \alpha}$ for $\lambda<1$.

In Lemma 4, if fixed cost differences are in an intermediate range and $\lambda<1$, there exists a level of productivity above which firms prefer acquisitions to new investment. The intuition is that high productivity firms, who are relatively constrained by revenues, can alleviate this constraint to some degree by acquiring another variety. 


\section{Selling}

To complete the discussion of options in the investment stage, I will now characterize the decision to sell and exit. As detailed above, firms that acquire pay the target firm $R_{a}$ for their capital and variety. Hence, a firm is indifferent between selling and doing nothing if $R_{a}=\pi(\alpha, k, 0)$. Labeling the productivity level at which this occurs as $\alpha_{s}$, the following lemma summarizes the choice between doing nothing and selling.

Lemma 5 The choice between selling $(S)$ and doing nothing $(N)$ as a function of productivity is summarized as follows:

$$
\begin{aligned}
\text { For } & \alpha \in\left[0, \underline{\alpha}_{s}\right], S \succ N \\
& \alpha \in\left(\underline{\alpha}_{s}, \infty\right), N \succ S
\end{aligned}
$$

Proof. Straighforward when noting that $\pi(\alpha, k, 0)$ is increasing in productivity.

In Lemma 5, the least productive firms sell. They simply do not earn enough profits in the product market.

\section{A.2 Equilibrium}

I will now prove that there exists an equilibrium for $\lambda$ close to one that conforms with the empirical section of the paper and the motivating plots in Figure 1. Before proving the equilibrium, I must specify the acquisition market clearing condition. Labeling $\Theta_{B}$ and $\Theta_{S}$ as the measures of buying and selling firms, respectively, the acquisition market clearing condition is written as:

$$
\int_{\alpha \in \Theta_{S}} g(\alpha) d \alpha=\int_{\alpha \in \Theta_{B}} g(\alpha) d \alpha
$$

I will offer a more precise characterization of (15) as I prove the equilibrium below.

To start my proof, I prove a result for any equilibrium when $\lambda=1$.

Lemma 6 If $\lambda=1$, any equilibrium must satisfy $R_{a} \leq F_{I}$.

Proof. Suppose to the contrary that $R_{a}>F_{I} . R_{a}>0$ implies that there exists a positive measure of selling firms. However, since $\Pi_{M}(\alpha \mid \lambda=1)=\Pi_{I}(\alpha)$, firms choose the option which minimizes fixed costs. When $R_{a}>F_{I}$, that option is new investment, and there is no acquisition demand. Hence, the acquisition market clearing condition in (15) is not satisfied. Thus, $R_{a}>F_{I}$ cannot be an equilibrium when $\lambda=1$

Next, I prove a result for an auxiliary game in which there is no option of new investment. In the full game, I will use this result to characterize the "type" of equilibrium.

Lemma 7 Suppose that new investment is not an option. For this case, there exists a value $R_{a}=\widehat{R}_{a}$ such that the acquisition market clearing condition in (15) is satisfied and the equilibrium sorting of firms is as follows.

$$
\text { For } \begin{aligned}
& \alpha \in\left[0, \alpha_{S}\right), \text { firms sell } \\
& \alpha \in\left[\alpha_{S}, \underline{\alpha}_{M}\right], \text { firms do nothing } \\
& \alpha \in\left(\underline{\alpha}_{M}, \bar{\alpha}_{M}\right) \text {, firms acquire } \\
& \alpha \in\left[\bar{\alpha}_{M}, \infty\right), \text { firms do nothing }
\end{aligned}
$$


Proof. First, I will prove optimal acquisition behavior for an arbitrary value of $R_{a}$ that is not trivially too large. Precisely, I will show that $\alpha_{S}<\underline{\alpha}_{M}<\bar{\alpha}_{M}$. Once I show this, the preference conditions are immediate from Lemmas 3 and 5.

The condition $\underline{\alpha}_{M}<\bar{\alpha}_{M}$ is satisfied by definition. To show that $\alpha_{S}<\underline{\alpha}_{M}$ first note that from the definitions of $\alpha_{S}$ and $\underline{\alpha}_{M}$ it must be the case that:

$$
\pi\left(\underline{\alpha}_{M}, k, k\right)-\pi\left(\underline{\alpha}_{M}, k, 0\right)=R_{a}=\pi\left(\alpha_{S}, k, 0\right)
$$

Rearranging,

$$
\frac{1}{2} \pi\left(\underline{\alpha}_{M}, k, k\right)-\pi\left(\underline{\alpha}_{M}, k, 0\right)=\pi\left(\alpha_{S}, k, 0\right)-\frac{1}{2} \pi\left(\underline{\alpha}_{M}, k, k\right)
$$

Since $\frac{1}{2} \pi\left(\underline{\alpha}_{M}, k, k\right)<\pi\left(\underline{\alpha}_{M}, k, 0\right)$ for $\lambda>0$ (diminishing returns to capital), the RHS must also be negative in equilibrium. This is only possible if $\alpha_{S}<\underline{\alpha}_{M}$.

Next, subject to this acquisition behavior, the acquisition market clearing condition is written as:

$$
\int_{0}^{\alpha_{S}} g(\alpha) d \alpha=\int_{\underline{\alpha}_{M}}^{\bar{\alpha}_{M}} g(\alpha) d \alpha
$$

It is straightforward to show that there exists a unique market clearing price $R_{a}=\widehat{R}_{a}$. By Lemma 5 , acquisition supply is rising in $R_{a}$ from zero. That is, the range $\left(0, \alpha_{S}\right)$ expands with higher $R_{a}$. Also, given the shape of $\Pi_{M}(\alpha)$, acquisition demand is falling in $R_{a}$, eventually reaching zero. That is, $\left(\underline{\alpha}_{M}, \bar{\alpha}_{M}\right)$ shrinks with $R_{a}$. Hence, by the intermediate value theorem, there exists a $R_{a}=\widehat{R}_{a}$ such that the acquisition market clears, subject to the equilibrium behavior summarized above.

Now, I am in a position to prove the three equilibrium cases of the model when $\lambda=1$.

Lemma 8 Suppose that $\lambda=1$. The equilibrium to the investment stage problem is as follows:

- If $F_{I}>\widehat{R}_{a}$, then $R_{a}=\widehat{R}_{a}<F_{I}$, no new investment occurs in equilibrium, and acquisition behavior occurs as summarized in Lemma $\%$.

- If $F_{I}=\widehat{R}_{a}$, then $R_{a}=\widehat{R}_{a}=F_{I}$, no new investment occurs in equilibrium, and acquisition behavior occurs as summarized in Lemma $\%$.

- If $F_{I}<\widehat{R}_{a}$, then $R_{a}=F_{I}$ and optimal investment decisions are characterized as follows:

$$
\text { For } \begin{aligned}
& \alpha \in\left[0, \alpha_{S}\right), \text { firms sell } \\
& \alpha \in\left[\alpha_{S}, \underline{\alpha}_{I}\right], \text { firms do nothing } \\
& \alpha \in\left(\underline{\alpha}_{I}, \bar{\alpha}_{I}\right), \text { firms acquire or invest in new capital } \\
& \alpha \in\left[\bar{\alpha}_{I}, \infty\right) \text {, firms do nothing }
\end{aligned}
$$

Here, $G\left(\alpha_{S}\right)$ firms acquire, and $G\left(\bar{\alpha}_{I}\right)-G\left(\underline{\alpha}_{I}\right)-G\left(\alpha_{S}\right)$ invest in new capital.

Proof. The key to proving both cases is nothing that $\Pi_{M}(\alpha \mid \lambda=1)=\Pi_{I}(\alpha)$. That is, product market incentives are identical for acquisitions and new investment when varieties within the firm are perfectly substitutable. Hence, firms choose the option that minimizes fixed costs. 
In the first case, where $F_{I}>\widehat{R}_{a}$, if firms choose only acquisitions, there exists a market clearing price at which the fixed cost of acquisitions is less than the fixed cost of new investment. Hence, new investment never occurs, and the equilibrium is identical to Lemma 7 . When the prices are equal, $F_{I}=\widehat{R}_{a}$, firms are indifferent between investment options, but to satisfy the acquisition market clearing condition, all firms must acquire. If some margin of firms decide to invest instead, the acquisition price will fall, leading all firms to acquire. Hence, when $F_{I}=\widehat{R}_{a}$, all firms must acquire.

When $F_{I}<\widehat{R}_{a}$, some new investment occurs in equilibrium. To see why, suppose that $R_{a}>F_{I}$. For this case, there is no acquisition demand since the acquisition price is greater than the fixed new investment cost. Thus, $R_{a}>F_{I}$ cannot be an equilibrium. When $R_{a}<F_{I}$, only acquisitions occur, but since $R_{a}<F_{I}<\widehat{R}_{a}, \widehat{R}_{a}$ being the price at which the acquisition market clears with no new investment, there is a shortage of selling firms, which pushes the acquisition price back up to $F_{I}$. At $R_{a}=F_{I}$, firms are indifferent between acquisitions and new investment, where firms randomly assign to investment and acquisitions to maintain the condition that $R_{a}=F_{I}$. Precisely, $G\left(\alpha_{S}\right)$ firms acquire, and $G\left(\bar{\alpha}_{I}\right)-G\left(\underline{\alpha}_{I}\right)-G\left(\alpha_{S}\right)$ invest in new capital. Any deviation from these shares results in one of the prior two conditions, which are not equilibria.

In Lemma 8, I have proven that there exist two types of equilibria when $\lambda=1$. When $F_{I}>\widehat{R}_{a}$, new investment does not occur since the fixed cost is too high relative to the acquisition price. In contrast, when $F_{I}<\widehat{R}_{a}$, the parameters of the model are such that there is insufficient supply of assets to satisfy acquisition demand relative to the additional option of new investment. Hence, the mechanism of the acquisition market halts when $R_{a}=F_{I}$, where firms then randomly sort into new investment and acquisitions such that the acquisition market clearing condition is satisfied.

At this point, I have proven that there exists a solution to the model in which new investment and acquisitions occur within a mid-range of productivity. This matches the features in the left panel in Figure 1. However, it does not show that as productivity increases, firms tend to prefer acquisitions. To see that this is also the case with this model, I will prove that when $\lambda$ is relatively close to 1 and $F_{I}$ is relatively low, there exists an equilibrium that exhibits all features of Figure 1. This result is summarized in the main proposition of the model.

Proposition 1 For $\lambda$ and $F_{I}$ such that $\lim _{\alpha \rightarrow \infty} \Pi_{M}(\alpha \mid \lambda)<\widehat{R}_{a}-F_{I}$, optimal investment decisions are characterized as follows:

$$
\text { For } \begin{aligned}
& \alpha \in\left[0, \alpha_{S}\right), \text { firms sell } \\
& \alpha \in\left[\alpha_{S}, \underline{\alpha}_{I}\right], \text { firms do nothing } \\
& \alpha \in\left(\underline{\alpha}_{I}, \alpha_{I M}\right), \text { firms invest in new capital } \\
& \alpha \in\left(\underline{\alpha}_{I M}, \bar{\alpha}_{M}\right), \text { firms acquire another firm } \\
& \alpha \in\left[\bar{\alpha}_{M}, \infty\right) \text {, firms do nothing }
\end{aligned}
$$

Further, the equilibrium acquisition price is in the range $F_{I}<R_{a}<\widehat{R_{a}}$

Proof. For $\lambda<1$, as detailed in section two, $\Pi_{M}(\alpha)>\Pi_{I}(\alpha)$ for all $\alpha$. If $R_{a}=F_{I}$, all firms within the region $\left(\underline{\alpha}_{I}, \bar{\alpha}_{I}\right)$ would acquire. However, acquisition supply falls short, where in Lemma $8, G\left(\bar{\alpha}_{I}\right)-G\left(\underline{\alpha}_{I}\right)>G\left(\alpha_{S}\right)$. Hence, there is excess demand for assets at $R_{a}=F_{I}$, which cannot be an equilibrium. 
Figure 4: Equilibrium - $\lambda$ close to $1, F_{I}$ not too large

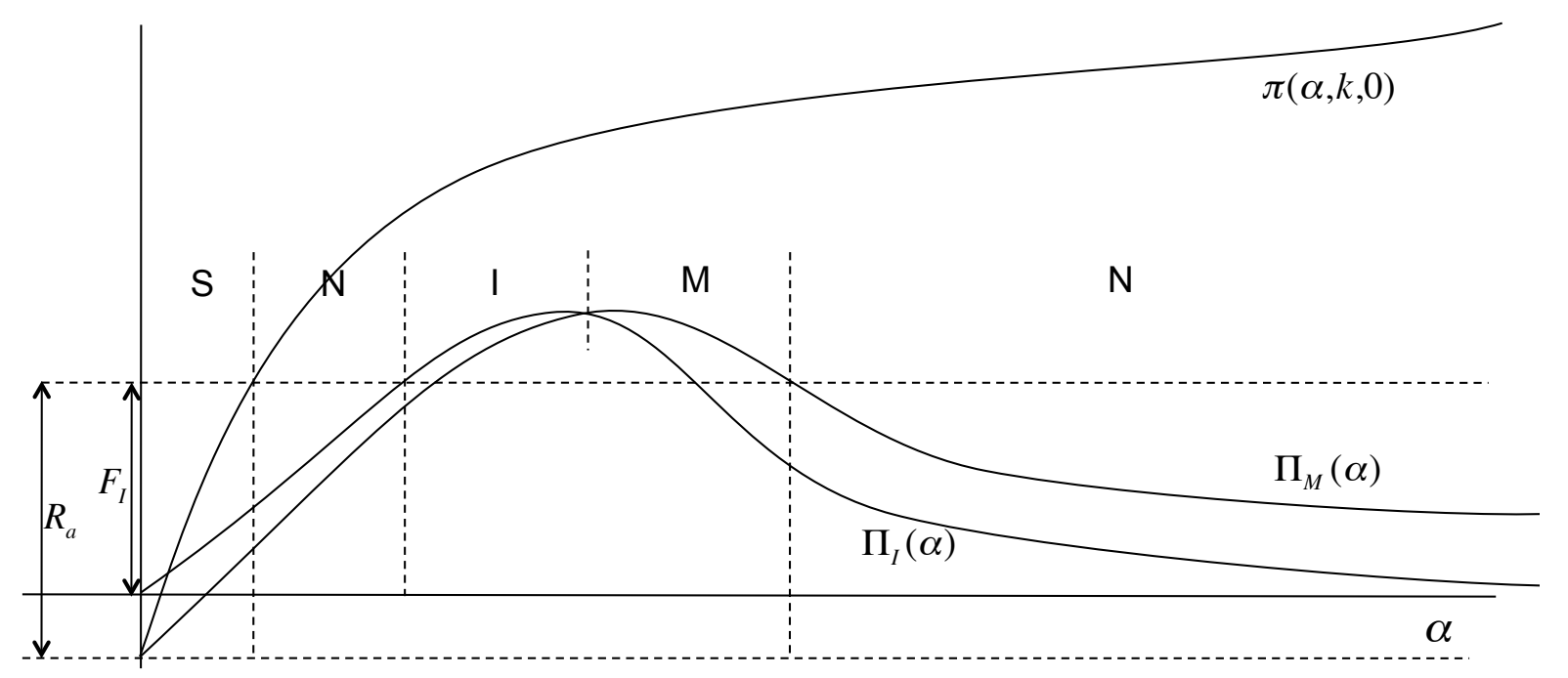

Next, suppose that $R_{a}=\widehat{R}_{a}$. For this case, acquisition demand is zero, since given that $F_{I}$ satisfies $\lim _{\alpha \rightarrow \infty} \Pi_{M}(\alpha \mid \lambda)<\widehat{R}_{a}-F_{I}$, no firms find an acquisition profitable relative to new investment (Lemma 4). On the supply side, there is a positive measure of selling firms, since $R_{a}>0$. Given the excess supply of selling firms, this cannot be an equilibrium.

In equilibrium, it must be the case that $F_{I}<R_{a}<\widehat{R}_{a}$. To derive the sorting for firms, note that since $R_{a}<\widehat{R}_{a}$, the share of firms that sell must be less than in the auxiliary game. However, the total share of firms that invest or acquire is larger than the auxiliary game, since both $F_{I}$ and $R_{a}$ are both less than $\widehat{R}_{a}$. Hence, it must be the case that both acquisitions and new investment occur when $F_{I}<R_{a}<\widehat{R}_{a}$. Given Lemma 4 implies that when $\lambda<1$ the benefit of acquisitions relative to new investment increases with productivity, we have the sorting of firms in the Proposition.

The equilibrium described in Proposition 1 is depicted in Figure 4. In equilibrium, the least productive firms sell, as the acquisition price is greater than the outside option of doing nothing, and both investment and acquisition provide paltry returns relative to fixed costs. Of the remaining active firms, those in a middle range of productivity invest, with the highest productivity firms in this range choosing acquisitions over new investment. Again, the key to the proof is that, when $\lambda$ is close to one and $F_{I}$ is relatively small $\left(\lim _{\alpha \rightarrow \infty} \Pi_{M}(\alpha \mid \lambda)<\widehat{R}_{a}-F_{I}\right)$, the share of investing firms must be larger than the share of firms that are willing to sell. Hence, some fraction of the investing firms must choose new investment over acquisitions, and given that $\lambda<1$, Lemma 4 requires that firms choosing new investment over acquisitions are relatively less productive. Hence, we have the sorting described in Proposition 1, and detailed in Figure 4. 


\section{B Technical Appendix - Demand Characteristics}

The primary result of the model is that mid productivity firms have the highest incentive to invest in new capital, and acquire when $\lambda$ is close to one. In deriving this result, the assumed demand function makes analysis particularly clean and instructive. However, this begs the following question: what are the general characteristics of demand required to deliver this particular result? To address this question, I will consider a monopolist producing subject to a general inverse demand function $P(q)$, and the same cost function as listed in (3).

Note that the crucial feature of the model is how the marginal value of additional capital changes with productivity. While $\frac{\partial \Pi}{\partial k}>0$ for every firm, and thus all firms earn some returns

from investment, $\frac{\partial^{2} \Pi}{\partial k \partial \alpha}$ may change sign depending on a firm's productivity level. The following proposition summarizes the properties of $\frac{\partial^{2} \Pi}{\partial k \partial \alpha}$.

Proposition $2 \frac{\partial \Pi}{\partial k}>0$ for all $\alpha$. Assuming that $\frac{\partial M R(q)}{\partial q}<0, \frac{\partial^{2} \Pi}{\partial k \partial \alpha}>0$ if $\frac{\partial M R(q)}{\partial q} \frac{q}{M R(q)}>-1$, and $\frac{\partial^{2} \Pi}{\partial k \partial \alpha}<0$ otherwise.

Proof. As in standard monopoly models, optimal output is determined by:

$$
P^{\prime} \cdot q+P=\frac{q}{\alpha k}
$$

By the envelope theorem, the marginal value of additional capital can be written as:

$$
\begin{aligned}
\frac{\partial \Pi}{\partial k} & =\underbrace{\left(P^{\prime} \cdot q+P-\frac{q}{\alpha k}\right)}_{=0} \frac{\partial q}{\partial k}+\frac{q^{2}}{\alpha k^{2}} \\
& =\frac{q^{2}}{\alpha k^{2}}>0
\end{aligned}
$$

Note that the marginal value of additional capital (net of capital costs) is always positive. Using (16), equation (17) can be written as:

$$
\frac{\partial \Pi}{\partial k}=\alpha\left(P^{\prime} \cdot q+P\right)^{2}=\alpha(M R(q))^{2}
$$

Differentiating with respect to $\alpha$, we get:

$$
\frac{\partial^{2} \Pi}{\partial k \partial \alpha}=(M R(q))^{2}+2 \alpha(M R(q)) \frac{\partial M R(q)}{\partial q} \frac{\partial q}{\partial \alpha}
$$

Note that using (16) $\frac{\partial q}{\partial \alpha}$ is written as,

$$
\frac{\partial q}{\partial \alpha}=\frac{k M R(q)}{1-\alpha k \frac{\partial M R(q)}{\partial q}}
$$


and thus $\frac{\partial^{2} \Pi}{\partial k \partial \alpha}$ is simplified as:

$$
\frac{\partial^{2} \Pi}{\partial k \partial \alpha}=\underbrace{(M R(q))^{2}}_{>0}(\overbrace{>0}^{\overbrace{1+\alpha k \frac{\partial M R(q)}{\partial q}}^{?}})
$$

In terms of the elasticity of the marginal revenue curve, substituting $\alpha k$ from (16), (18) can be rewritten as:

$$
\frac{\partial^{2} \Pi}{\partial k \partial \alpha}=\underbrace{(M R(q))^{2}}_{>0}(\underbrace{\overbrace{\underbrace{?}_{1+\frac{\partial M R(q)}{\partial q} \frac{q}{M R(q)}}}^{1-\frac{\partial M R(q)}{\partial q} \frac{q}{M R(q)}}}_{>0})
$$

For any demand function with a finite slope, as $q$ approaches zero, $\frac{\partial M R(q)}{\partial q} \frac{q}{M R(q)}$ approaches zero, and thus $\frac{\partial^{2} \Pi}{\partial k \partial \alpha}>0$. The critical question is how $\frac{\partial M R(q)}{\partial q} \frac{q}{M R(q)}$ is valued for high $q$ (higher productivity) firms. To study this condition, consider first the polar cases of price taking firms, and the standard CES demand function. With the former, marginal revenue does not change with quantity and $\frac{\partial^{2} \Pi}{\partial k \partial \alpha}>0$ for all $\alpha$. For the later, $\frac{\partial M R(q)}{\partial q} \frac{q}{M R(q)} \in(-1,0)$ when monopolists operate on the elastic portion of the CES demand curve, and hence, $\frac{\partial^{2} \Pi}{\partial k \partial \alpha}>0$ for all $\alpha$. In contrast, for linear demand, $\frac{\partial M R(q)}{\partial q} \frac{q}{M R(q)}=-\frac{2 \gamma q}{A-2 \gamma q}$, where $\frac{\partial M R(q)}{\partial q} \frac{q}{M R(q)}<-1$ when $q>\frac{A}{4 \gamma}$, or in terms of productivity, $\alpha>\frac{1}{2 \gamma k}$.

Generally, a mid productivity firm will have the highest marginal value of capital as long as $\frac{\partial M R(q)}{\partial q} \frac{q}{M R(q)}$ is decreasing over all $q$, and does not asymptote to a value above negative one. On the other hand, if the demand function is sufficiently convex, and $\frac{\partial M R(q)}{\partial q} \frac{q}{M R(q)}$ is everywhere greater than negative one, then investment incentives will be increasing in productivity.

\section{Empirical Appendix}

\section{C.1 Sales per worker}

In section two, investment decisions are derived as a function of endowed firm-level productivity, $\alpha$. However, as is clear from (9) and (10), the important factor specific to each firm is not the productivity level, but the capital adjusted productivity level, $\alpha k$. Conveniently, this can be directly related to a readily observable measure of productivity - sales per worker. 
To see this, first note from above that optimal pre-investment quantity and price are written as:

$$
\begin{aligned}
q(\alpha k) & =\frac{A \alpha k}{2 \gamma \alpha k+1} \\
p(\alpha k) & =A \frac{\gamma \alpha k+1}{2 \gamma \alpha k+1}
\end{aligned}
$$

Thus, sales of each variety can be written as:

$$
\operatorname{Sales}(\alpha k)=A^{2} \alpha k \frac{(\gamma \alpha k+1)}{(2 \gamma \alpha k+1)^{2}}
$$

Next, note that from the assumed cost function in (3), variable input requirements are equal to $\frac{q^{2}}{\alpha k}$. Assuming that labor is the primary variable input, optimal labor procurement as a function of capital adjusted productivity is written as:

$$
L(\alpha k)=\frac{A^{2} \alpha k}{(2 \gamma \alpha k+1)^{2}}
$$

Thus, the pre-acquisition level of sales per worker is written as:

$$
\frac{\text { Sales }}{L}(\alpha k)=(\gamma \alpha k+1)
$$

Clearly, within a given industry (in which the parameter $\gamma$ is common across firms), sales per worker is linearly related to the critical term of interest, $\alpha k$. Defining $\widetilde{S} \equiv \frac{\text { Sales }}{L}(\alpha k)-1=\gamma \alpha k>0$ as an adjusted sales per worker, I can thus estimate $\alpha k$ by controlling for any industry-year specific effects embodied in $\gamma$.

\section{C.2 HHI Proof}

In this appendix, I prove that, holding $S_{k, t}$ fixed, $\frac{\partial H H I_{k, t}}{\partial \gamma}<0$. Recall that:

$$
H H I_{k, t}=\frac{\sum_{i \in S_{k, t}} \text { Sales }_{i, t}^{2}}{\left(\sum_{i \in S_{k, t}} \text { Sales }_{i, t}\right)^{2}}
$$

First, substitute for Sales $_{k, t}$ from the definition of pre-acquisition sales in Sales $(\alpha k)$ in (20).

$$
H H I_{k, t}=\frac{\sum_{i \in S_{k, t}}\left(\frac{A^{2} \alpha_{i} k\left(\gamma \alpha_{i} k+1\right)}{\left(2 \gamma \alpha_{i} k+1\right)^{2}}\right)^{2}}{\left(\sum_{i \in S_{k, t}} \frac{A^{2} \alpha_{i} k\left(\gamma \alpha_{i} k+1\right)}{\left(2 \gamma \alpha_{i} k+1\right)^{2}}\right)^{2}}
$$

Clearly, the $A^{2}$ terms in $H H I_{k, t}$ can be cancelled out. Defining $\phi_{i}=\frac{\alpha_{i} k\left(\gamma \alpha_{i} k+1\right)}{\left(2 \gamma \alpha_{i} k+1\right)^{2}}$, we have:

$$
H H I_{k, t}=\frac{\sum_{i \in S_{k, t}} \phi_{i}^{2}}{\left(\sum_{i \in S_{k, t}} \phi_{i}\right)^{2}}
$$


Differentiating with respect to $\gamma$, and dropping $t^{\prime} s$ for convenience, we have:

$$
\frac{\partial H H I_{k}}{\partial \gamma}=\frac{2}{\left(\sum_{i \in S_{k}} \phi_{i}\right)^{3}}\left(\sum_{i \in S_{k}} \phi_{i} \frac{\partial \phi_{i}}{\partial \gamma} \sum_{i \in S_{k}} \phi_{i}-\sum_{i \in S_{k}} \phi_{i}^{2} \sum_{i \in S_{k}} \frac{\partial \phi_{i}}{\partial \gamma}\right)
$$

Note that $\frac{\partial \phi_{i}}{\partial \gamma}=-\phi_{i} \lambda_{i}$, where $\lambda_{i}=\frac{2 \gamma\left(\alpha_{i} k\right)^{2}+3 \alpha_{i} k}{\gamma\left(2 \gamma\left(\alpha_{i} k\right)^{2}+3 \alpha_{i} k\right)+1}$. Substituting $-\phi_{i} \lambda_{i}$ for $\frac{\partial \phi_{i}}{\partial \gamma}$, we have:

$$
\frac{\partial H H I_{k}}{\partial \gamma}=-\frac{2}{\left(\sum_{i \in S_{k}} \phi_{i}\right)^{3}}\left(\sum_{i \in S_{k}} \phi_{i}^{2} \lambda_{i} \sum_{i \in S_{k}} \phi_{i}-\sum_{i \in S_{k}} \phi_{i}^{2} \sum_{i \in S_{k}} \phi_{i} \lambda_{i}\right)
$$

Further simplification yields:

$$
\frac{\partial H H I_{k}}{\partial \gamma}=-\frac{2}{\left(\sum_{i \in S_{k}} \phi_{i}\right)^{3}}\left(\sum_{i \in S_{k}} \sum_{j \in S_{k}} \phi_{i}^{2} \phi_{j}\left(\lambda_{i}-\lambda_{j}\right)\right)
$$

To sign $\sum_{i \in S_{k}} \sum_{j \in S_{k}} \phi_{i}^{2} \phi_{j}\left(\lambda_{i}-\lambda_{j}\right)$, note that for any pair of varieties $l$ and $k$ (that is adding $\phi_{i}^{2} \phi_{j}\left(\lambda_{i}-\lambda_{j}\right)$ when $i=l, j=k$ and $\left.i=k, j=l\right)$, the components of the double summation can be written as $\phi_{l}^{2} \phi_{k}\left(\lambda_{l}-\lambda_{k}\right)+\phi_{k}^{2} \phi_{l}\left(\lambda_{k}-\lambda_{l}\right)$. This can be simplified as:

$$
\begin{aligned}
\phi_{l}^{2} \phi_{k}\left(\lambda_{l}-\lambda_{k}\right)+\phi_{k}^{2} \phi_{l}\left(\lambda_{k}-\lambda_{l}\right) & =\phi_{l} \phi_{k}\left(\phi_{l}\left(\lambda_{l}-\lambda_{k}\right)+\phi_{k}\left(\lambda_{k}-\lambda_{l}\right)\right) \\
& =\phi_{l} \phi_{k}\left(\phi_{l}-\phi_{k}\right)\left(\lambda_{l}-\lambda_{k}\right)
\end{aligned}
$$

It is straightforward to show that $\phi$ and $\lambda$ are both increasing in $\alpha$. Hence, when $\alpha_{l} \neq \alpha_{k}$, $\phi_{l} \phi_{k}\left(\phi_{l}-\phi_{k}\right)\left(\lambda_{l}-\lambda_{k}\right)>0$. When $\alpha_{l}=\alpha_{k}$, then $\phi_{l} \phi_{k}\left(\phi_{l}-\phi_{k}\right)\left(\lambda_{l}-\lambda_{k}\right)=0$. Overall, as long as there is some variation in productivity, $\sum_{i \in S_{k}} \sum_{j \in S_{k}} \phi_{i}^{2} \phi_{j}\left(\lambda_{i}-\lambda_{j}\right)>0$, and hence, $\frac{\partial H H I_{k}}{\partial \gamma}<0$. 
Figure 5: Baseline Nonparametric Results - Sales Per Worker
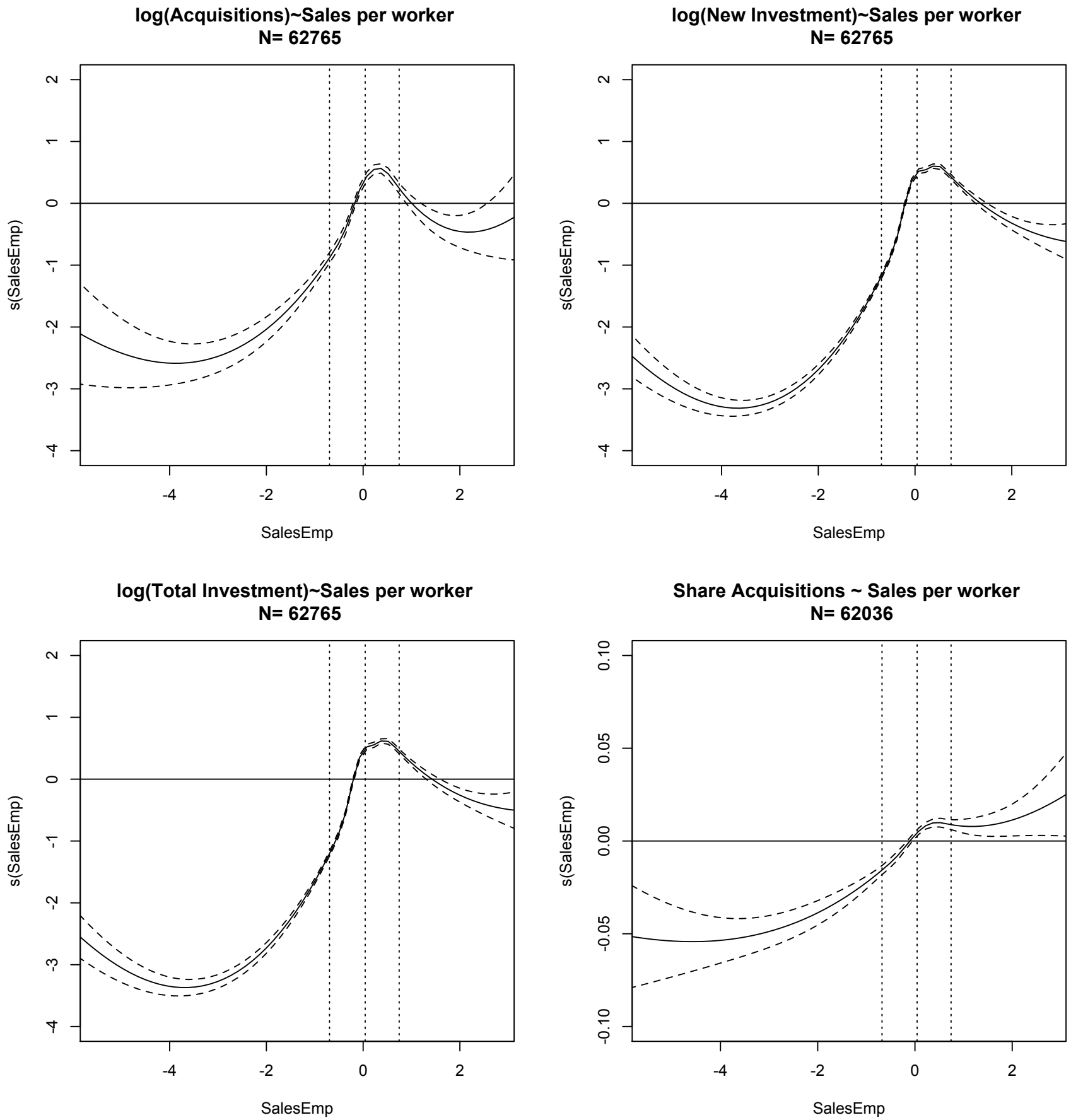

Notes: Each panel illustrates the relative value of an investment type (Acquisitions, New Investment, Total Investment, and Acquisition Share) as a function of SalesEmp (Sales per Worker). Year, foreign incorporation, and SIC fixed effects are used for each panel. The expected value of $\mathrm{s}$ (SalesEmp) is normalized to zero for identification. 90\% Bayesian confidence intervals are provided. The vertical dashed lines represent (from left to right) the 10th, 50th, and 90th percentiles of the productivity measure. Due to outliers (which are included in the estimation) the figures are trimmed at the 0.1th and 99.9th percentile of SalesEmp to improve clarity. 
Figure 6: Baseline Nonparametric Results - Sales Per Worker AR1
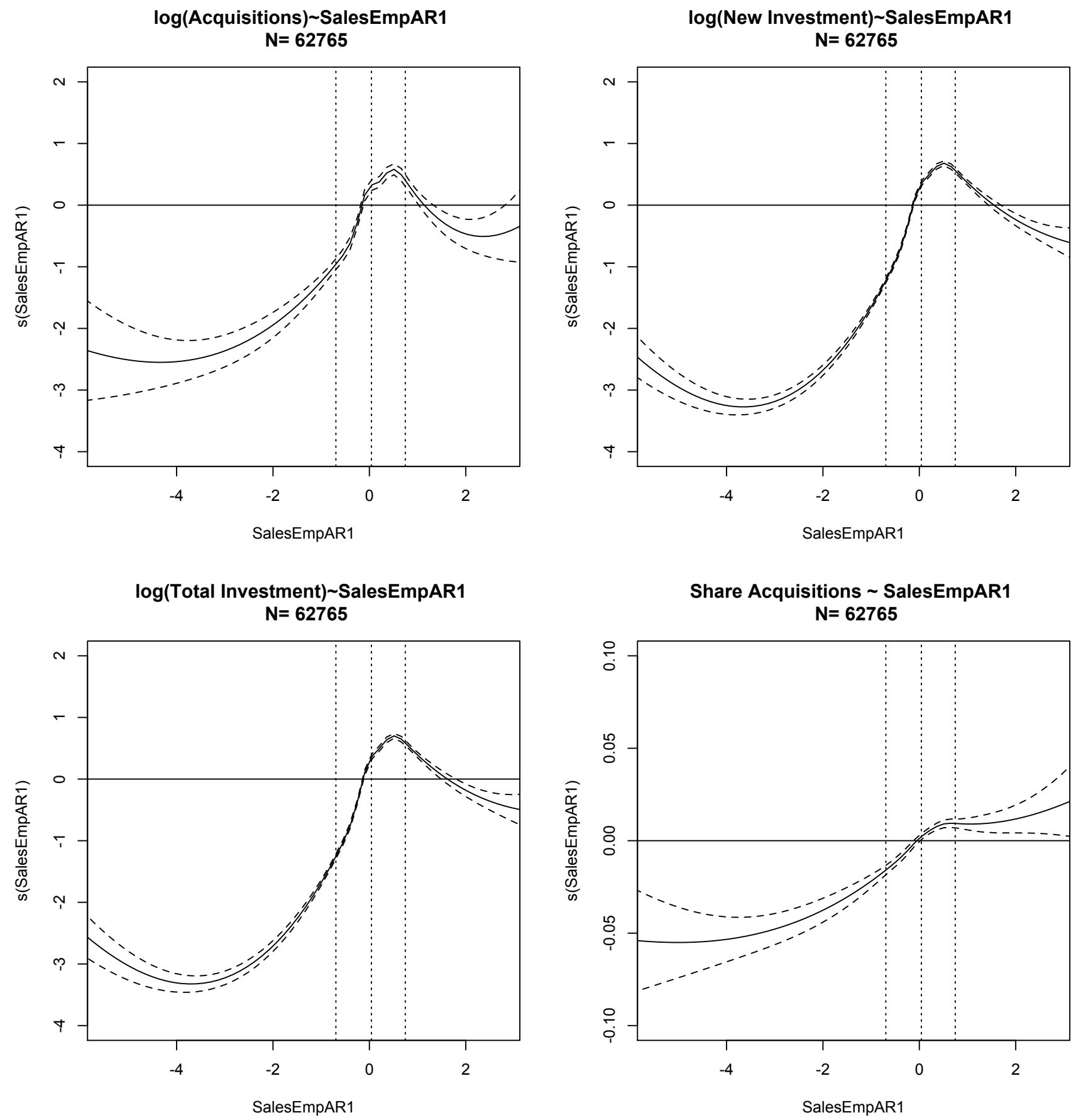

Notes: Each panel illustrates the relative value of an investment type (Acquisitions, New Investment, Total Investment, and Acquisition Share) as a function of SalesEmpAR1. Year, foreign incorporation, and SIC fixed effects are used for each panel. The expected value of $\mathrm{s}$ (SalesEmpAR1) is normalized to zero for identification. $90 \%$ Bayesian confidence intervals are provided. The vertical dashed lines represent (from left to right) the 10th, 50th, and 90th percentiles of the productivity measure. Due to outliers (which are included in the estimation) the figures are trimmed at the 0.1th and 99.9th percentile of SalesEmp to improve clarity. 
Figure 7: Baseline Nonparametric Results - TFP
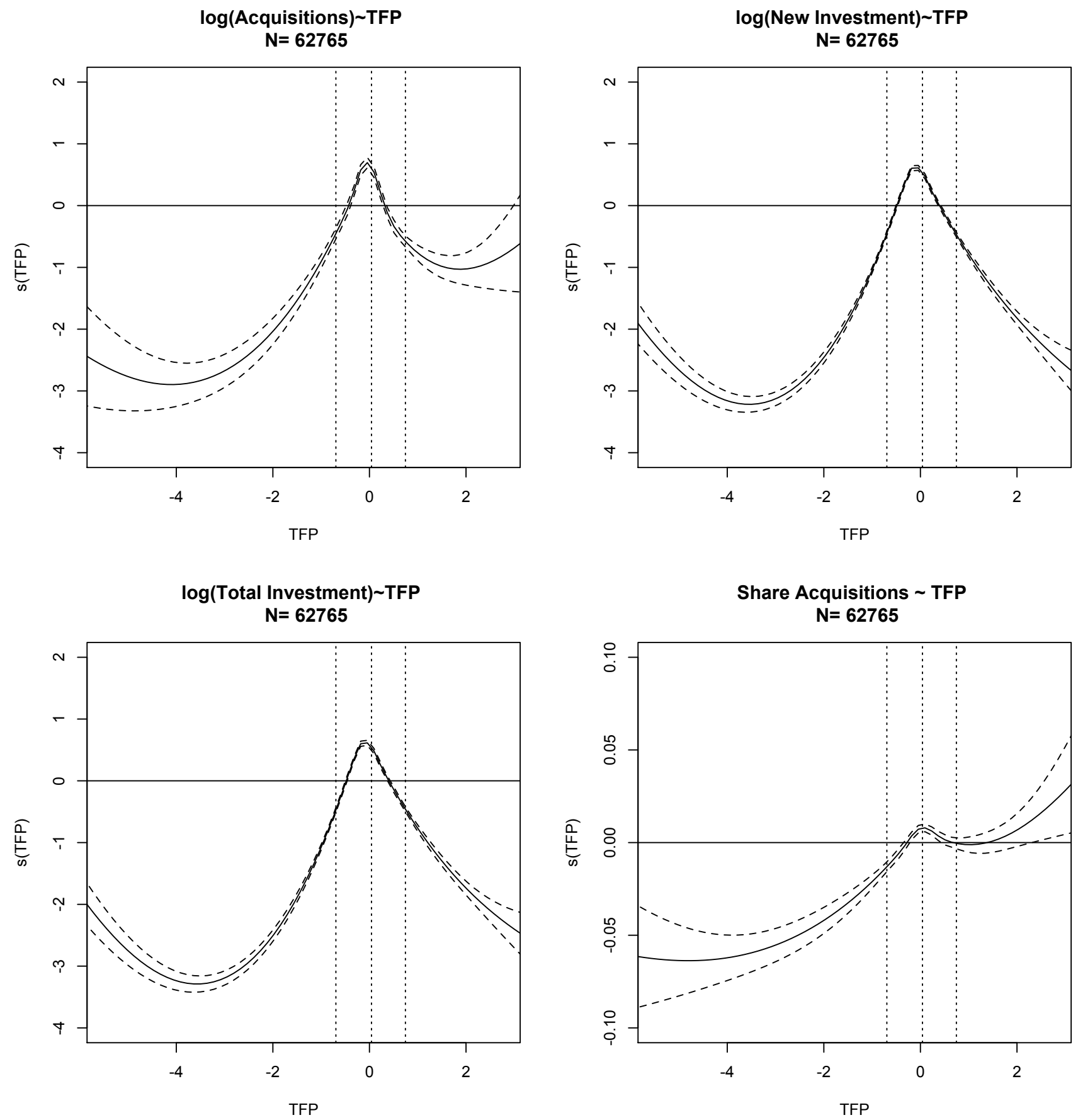

Notes: Each panel illustrates the relative value of an investment type (Acquisitions, New Investment, Total Investment, and Acquisition Share) as a function of TFP. Year, foreign incorporation, and SIC fixed effects are used for each panel. The expected value of $\mathrm{s}(\mathrm{TFP})$ is normalized to zero for identification. 90\% Bayesian confidence intervals are provided. The vertical dashed lines represent (from left to right) the 10th, 50th, and 90th percentiles of the productivity measure. Due to outliers (which are included in the estimation) the figures are trimmed at the 0.1th and 99.9th percentile of TFP to improve clarity. 

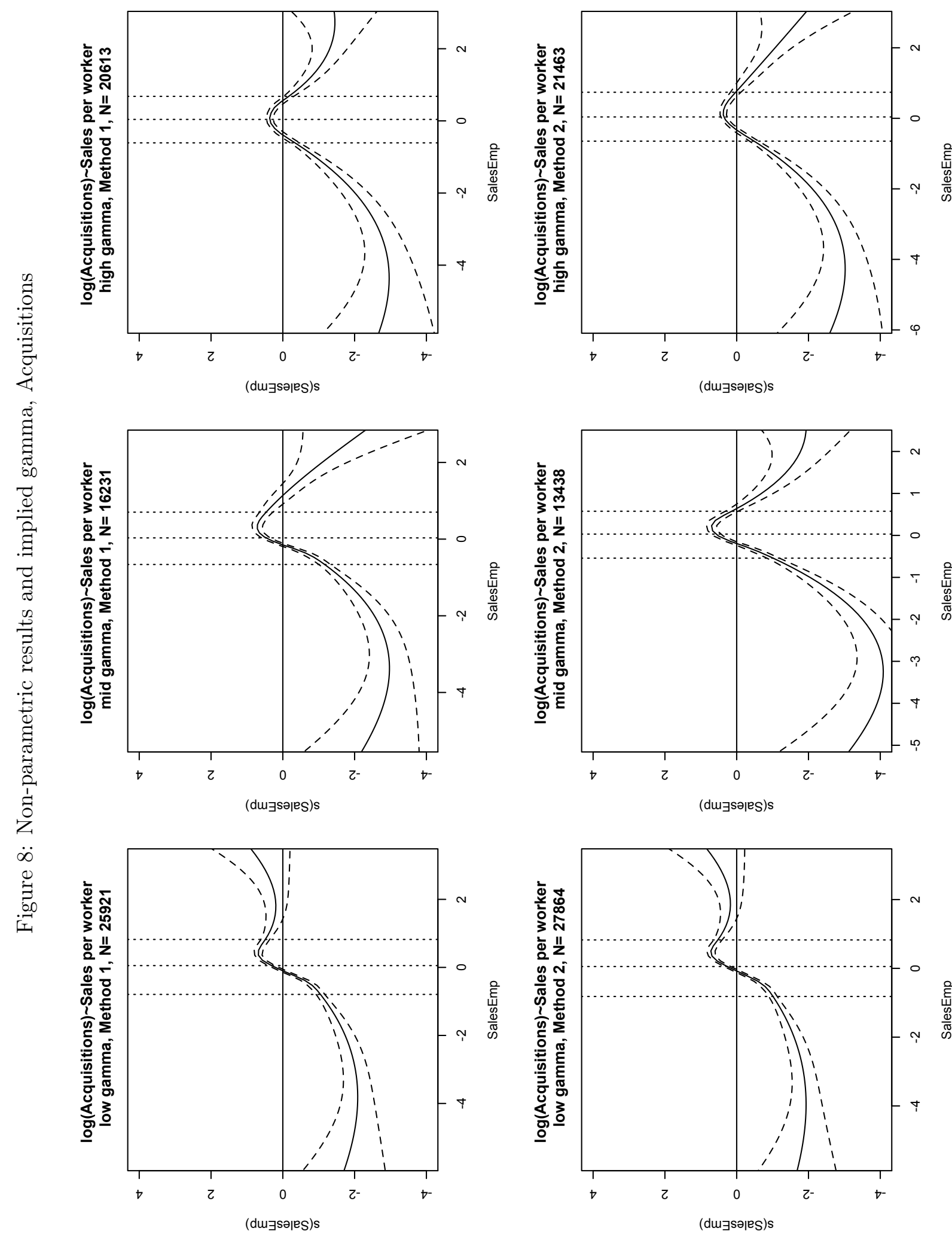

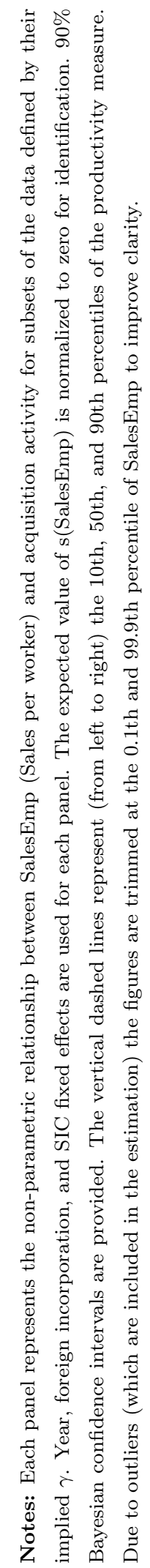



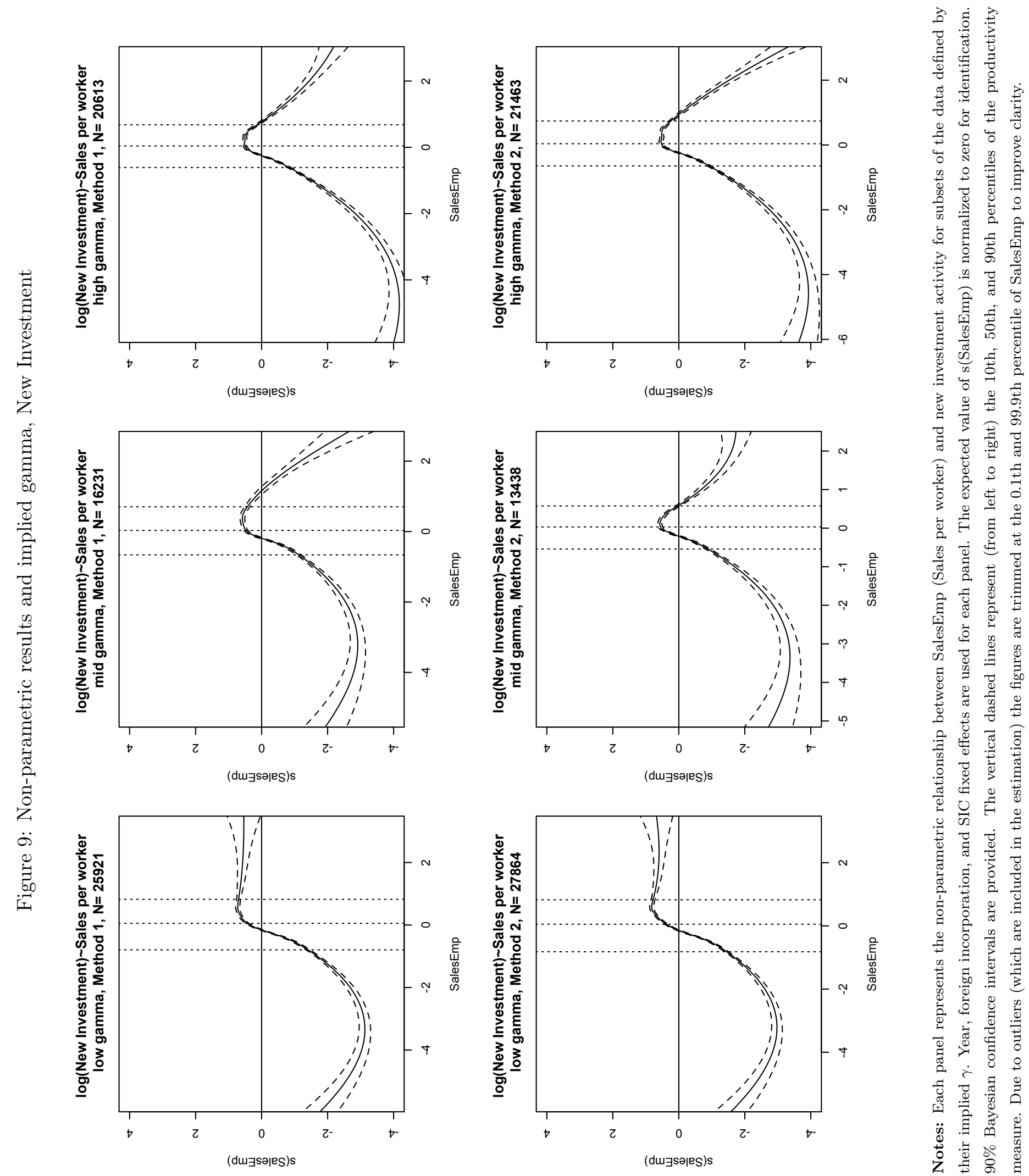

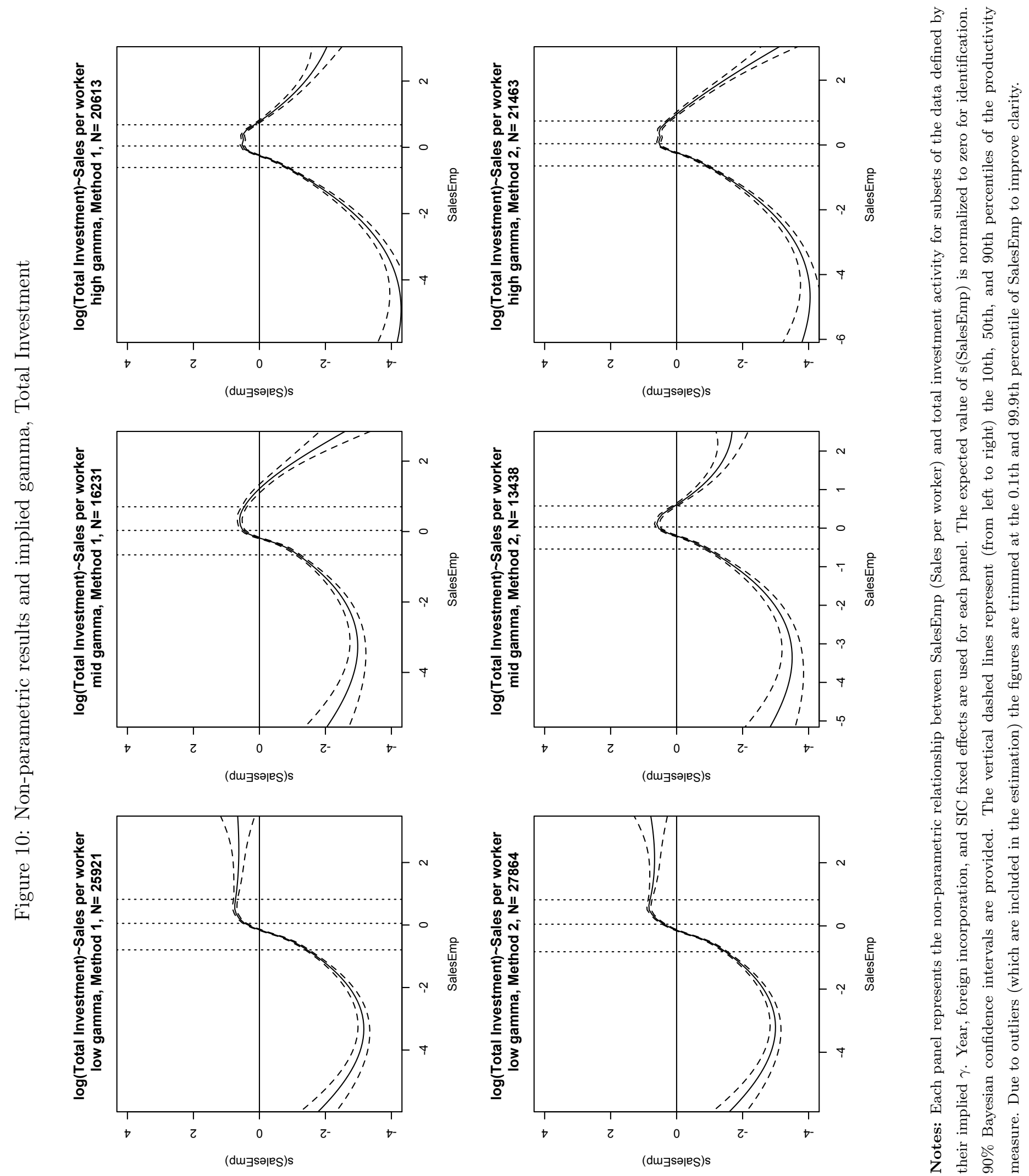

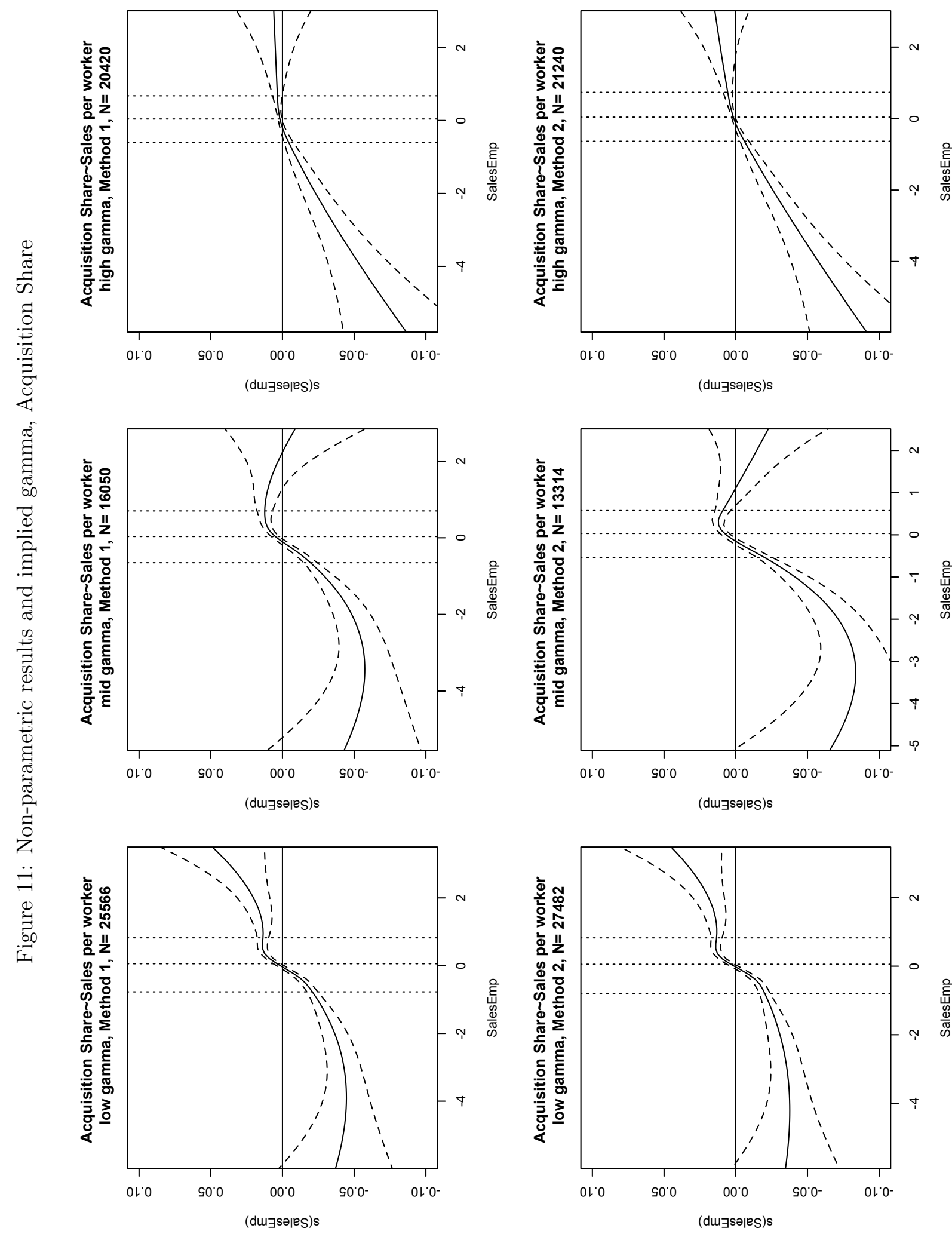

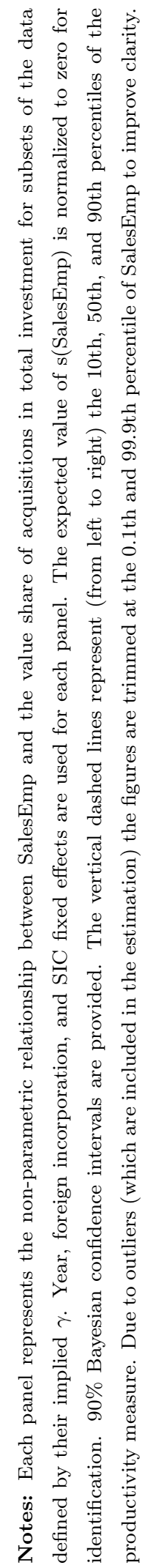



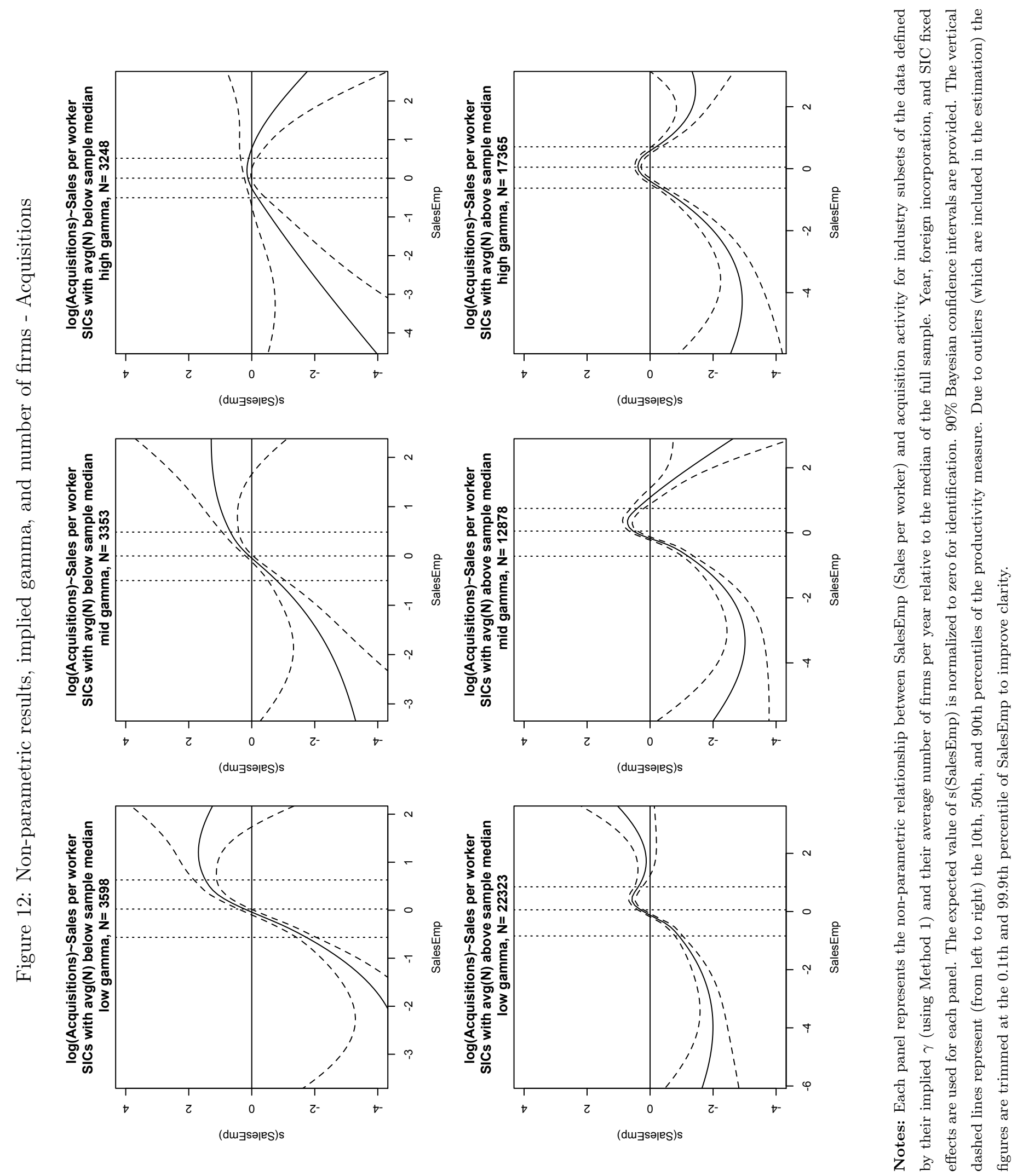

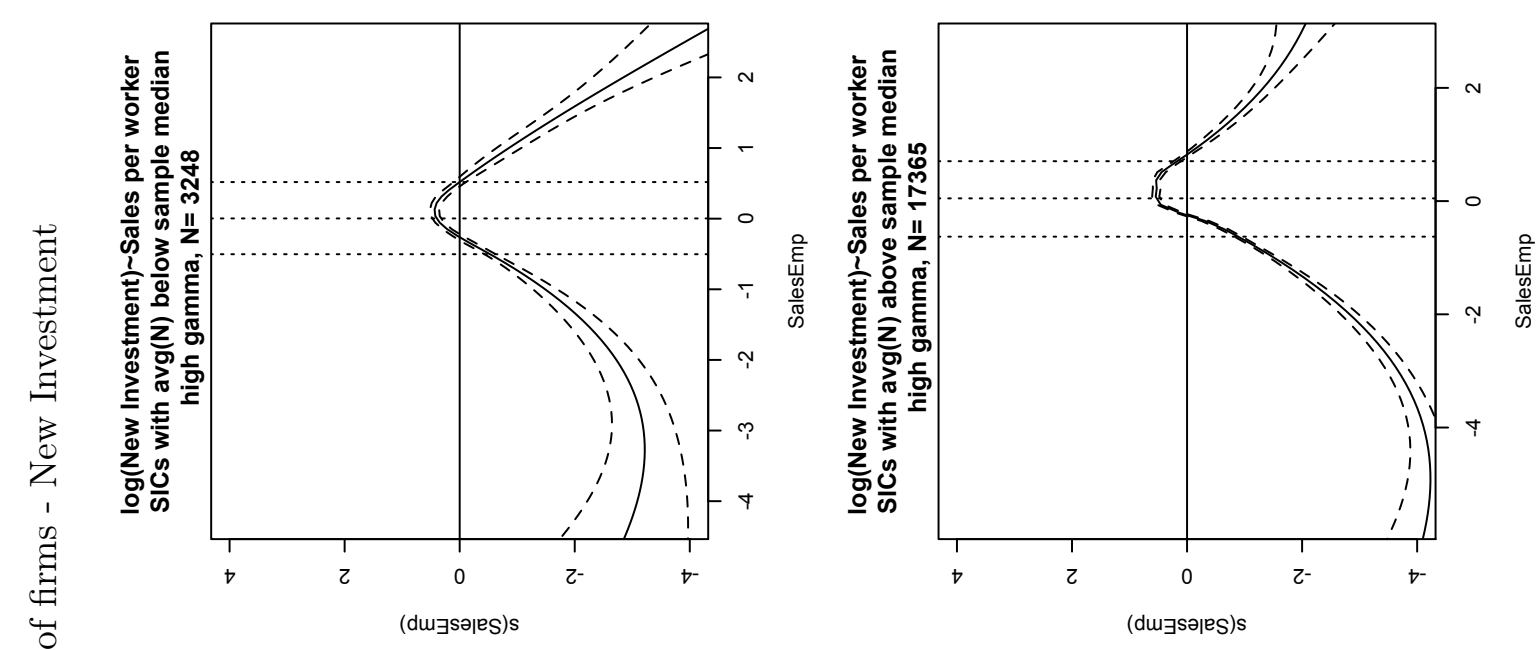

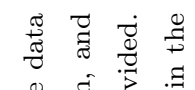

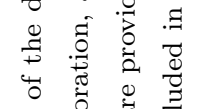

$\begin{array}{cccc}0 & 0 & 0 & \Xi \\ 0 & 0 & 0 \\ 0 & 0 & 0 \\ 0 & 0 & 0 \\ 0 & 0 & 0 \\ 0 & 0 & 0\end{array}$

क

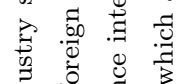

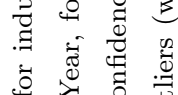

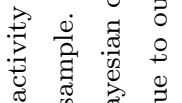

苞芯

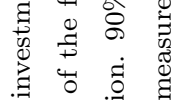

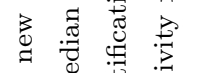
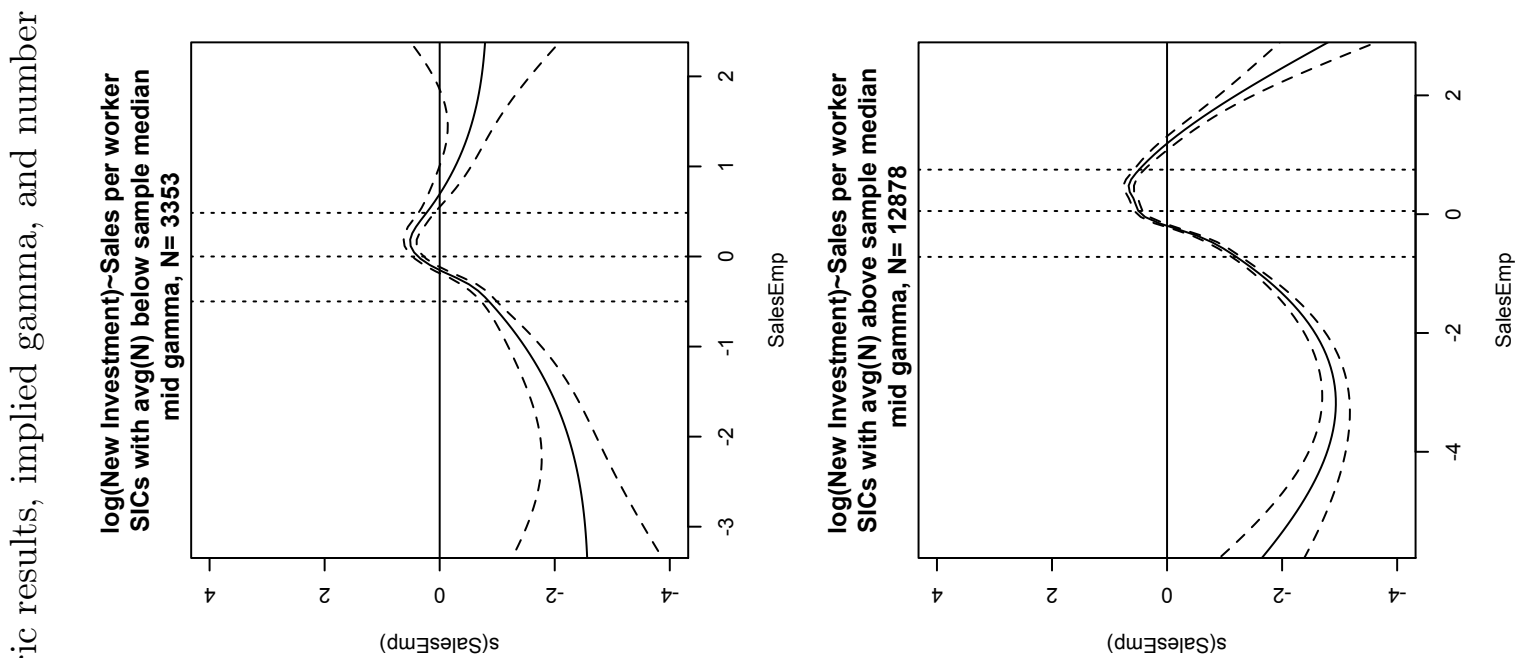

चี

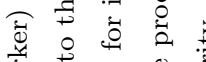

ప艹

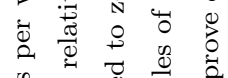

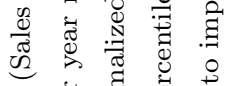

दे

预 है

थ पू द्वि च्ञ

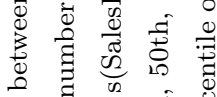

.

苟

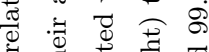

.

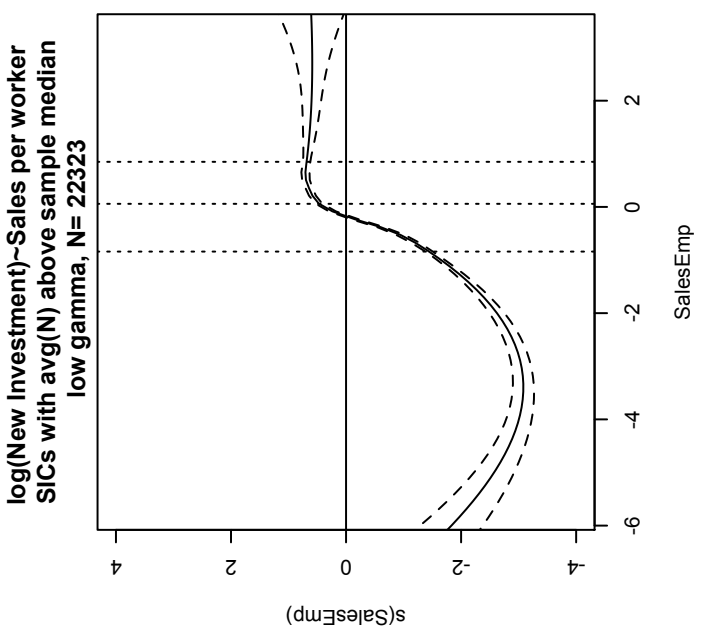

苞

घี

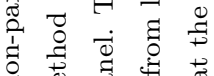

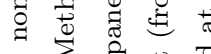

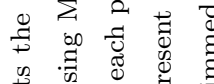

褐

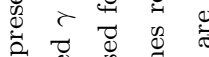

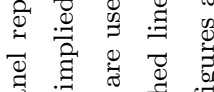

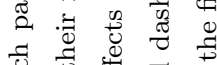

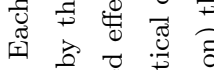

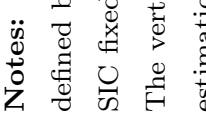



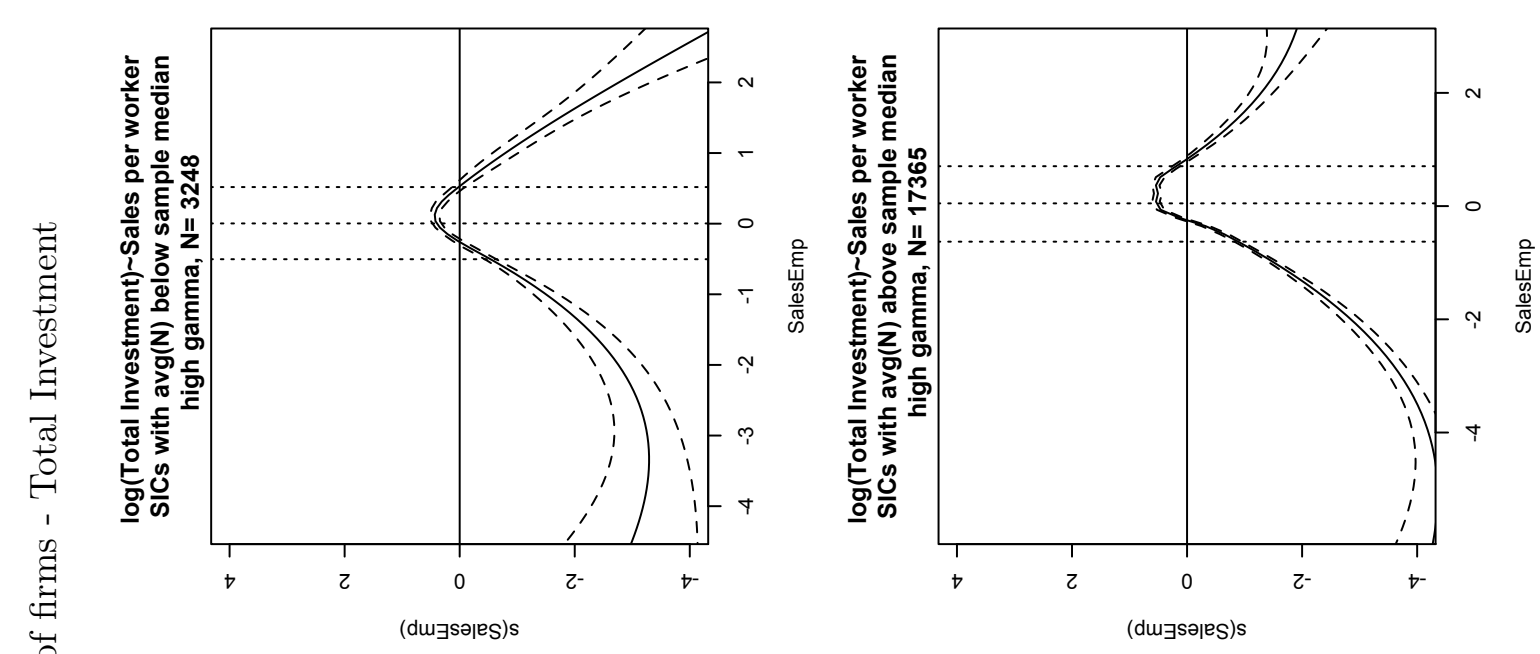

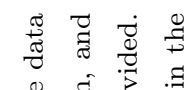

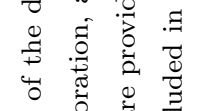

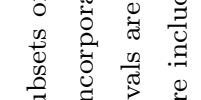

范

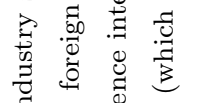

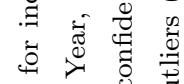

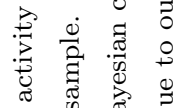
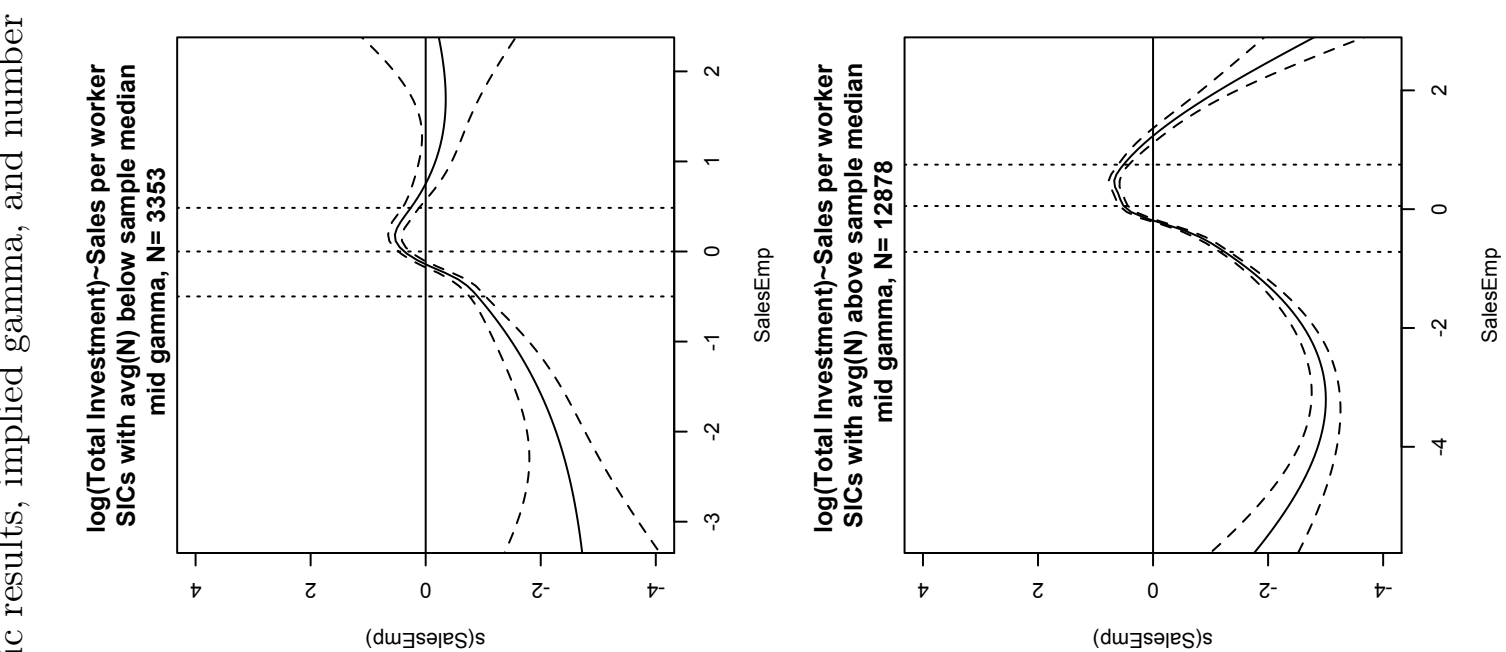

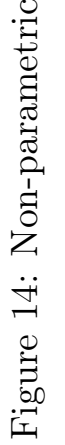
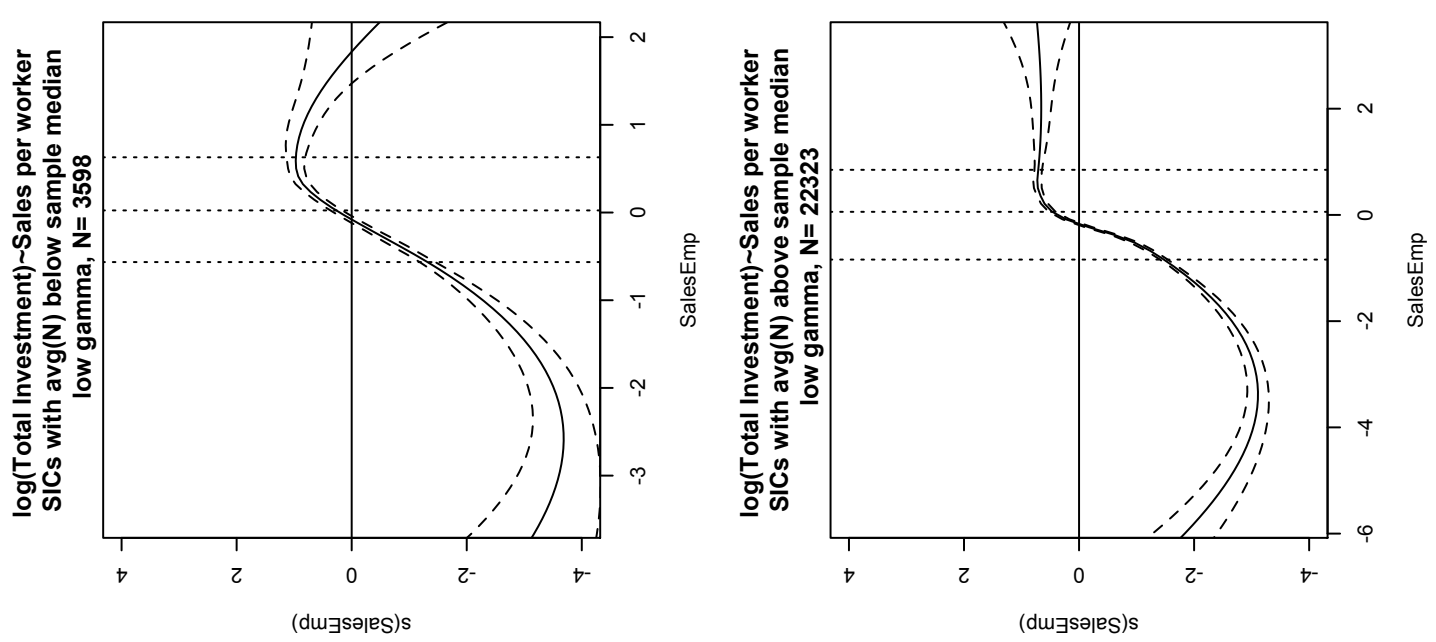

言苛焉

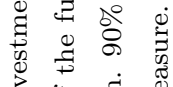

当

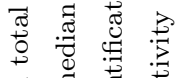

चี

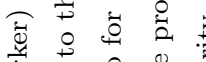

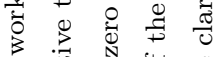

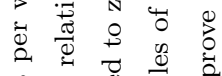

㻤

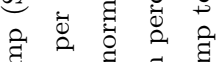

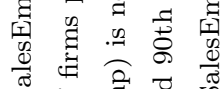

तू पू द्वे चू

न

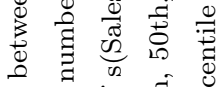

娄

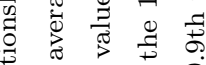

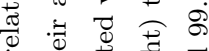

‡

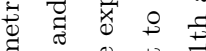

跑

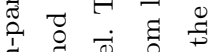

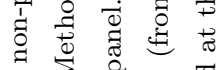

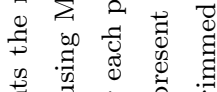

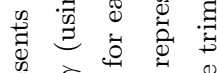

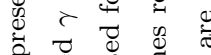

苞

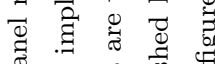

员.

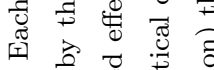

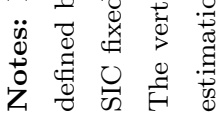



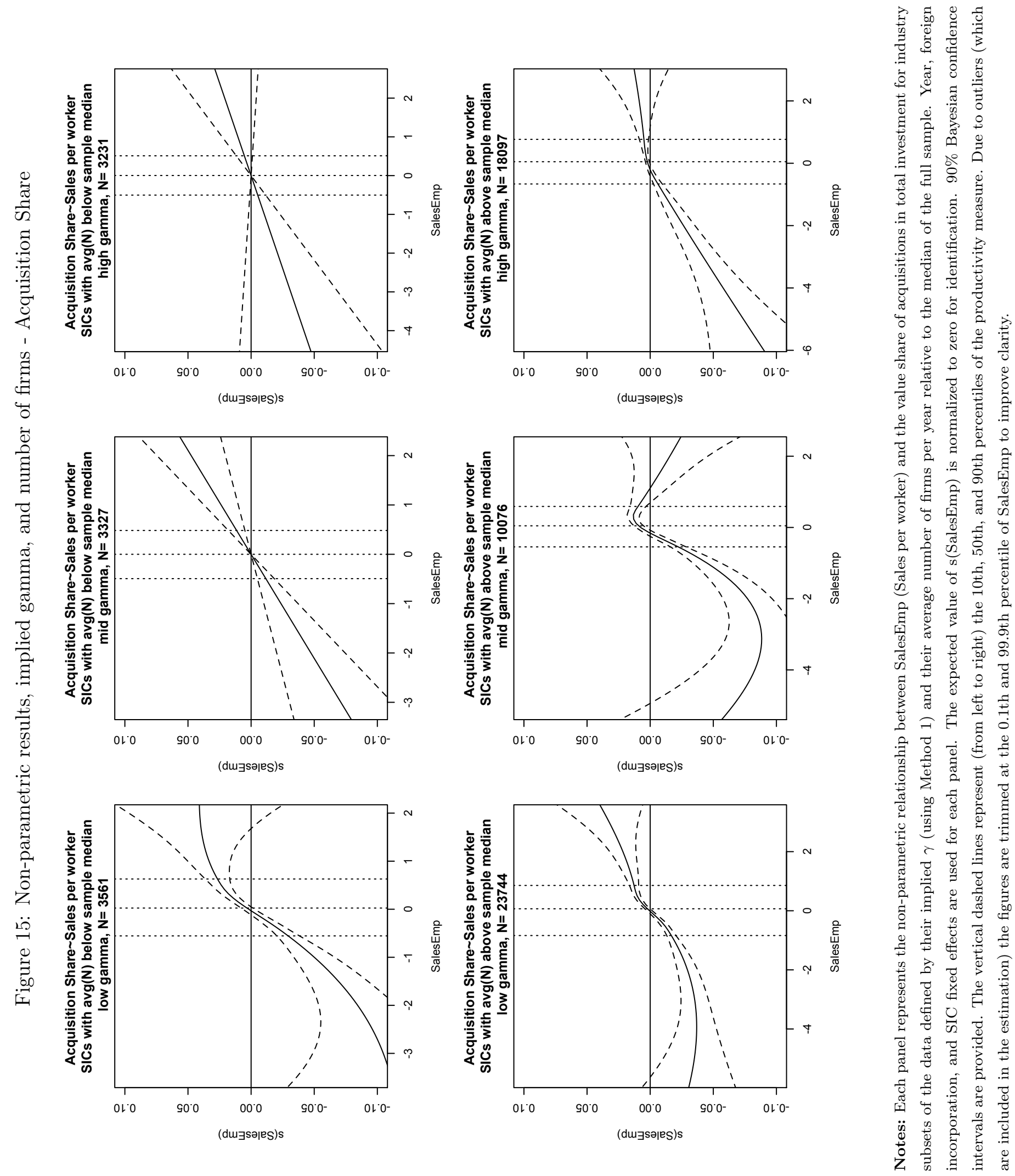

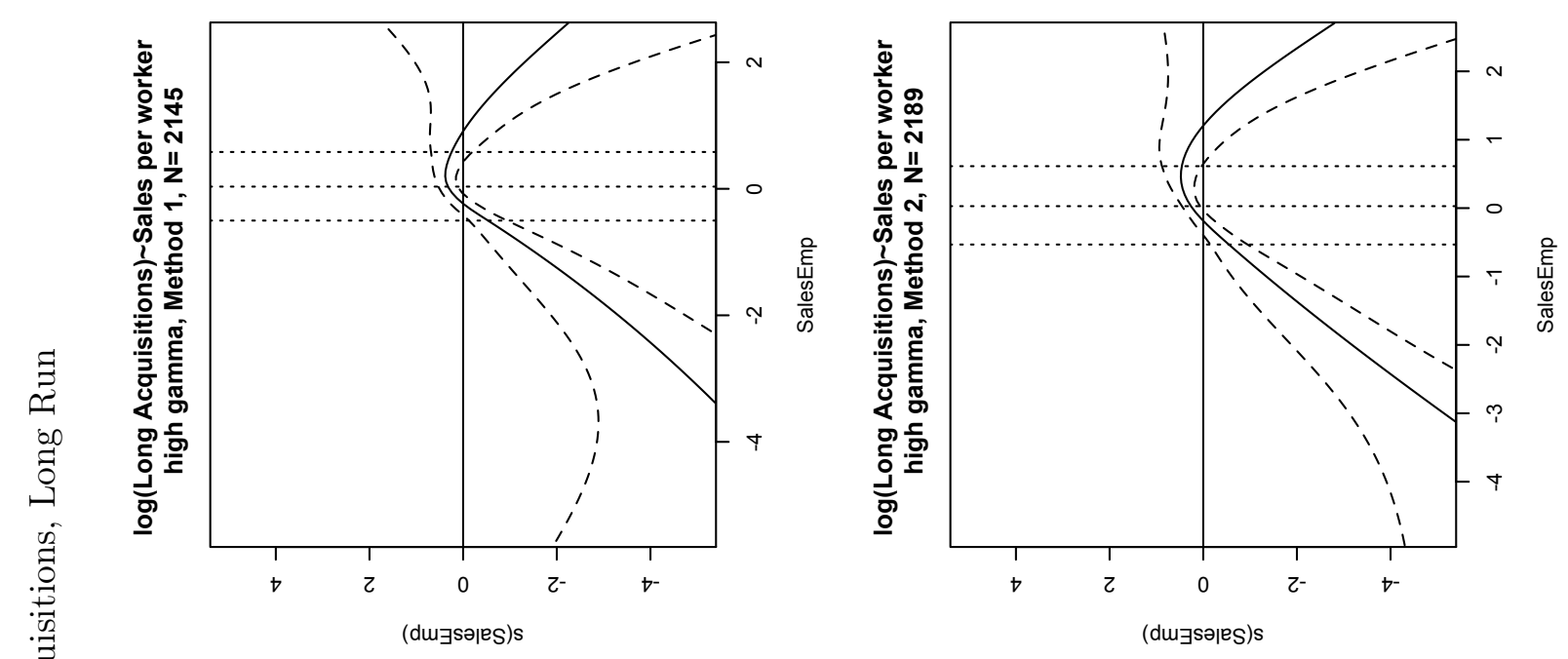

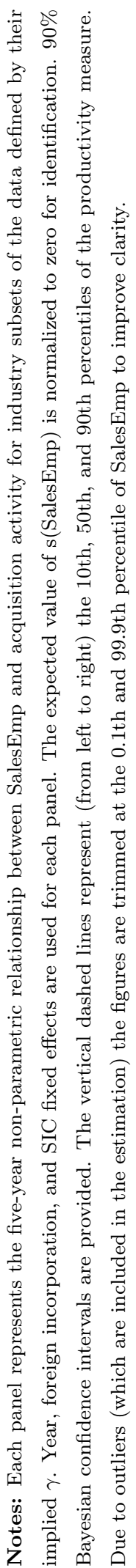
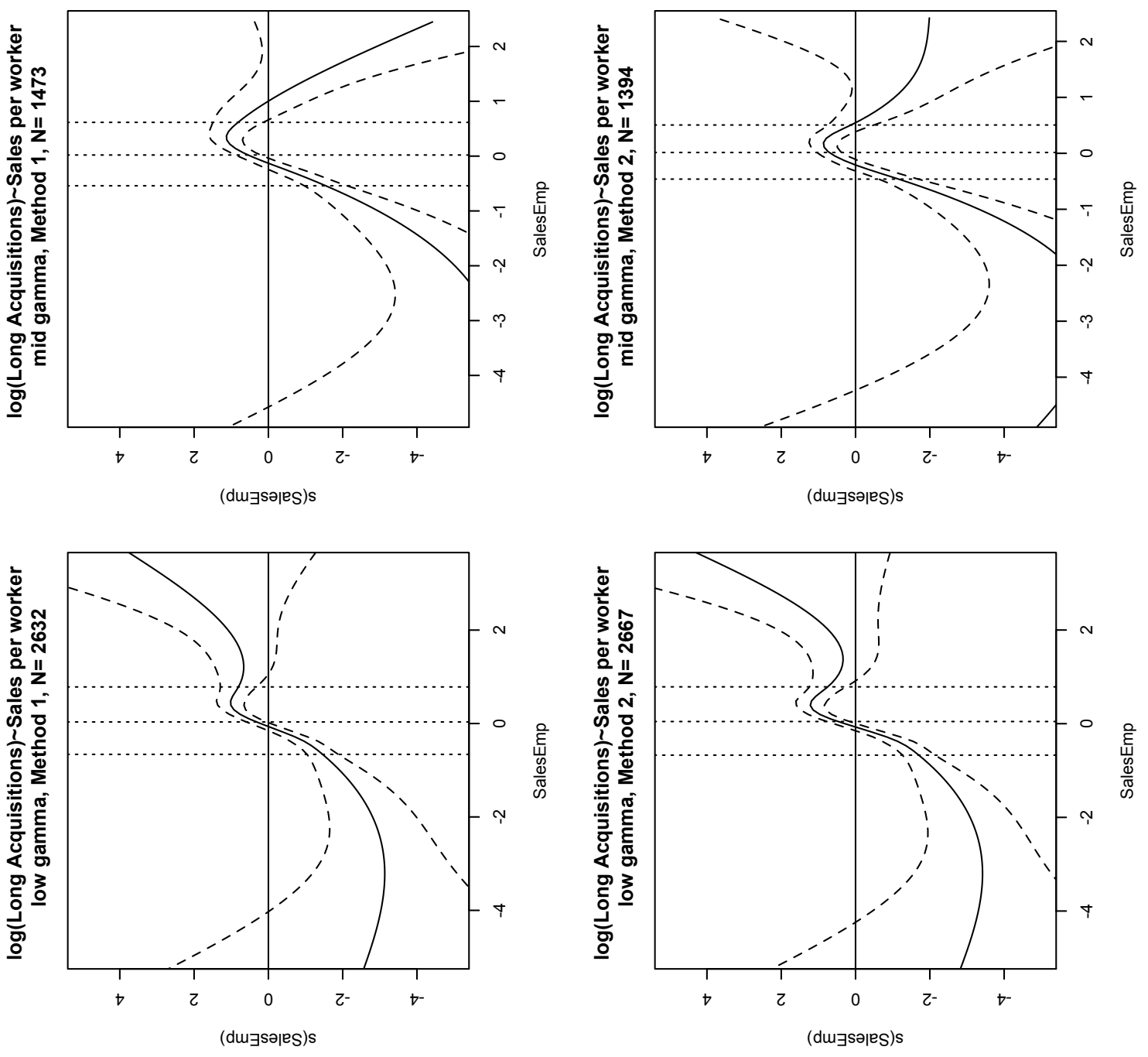

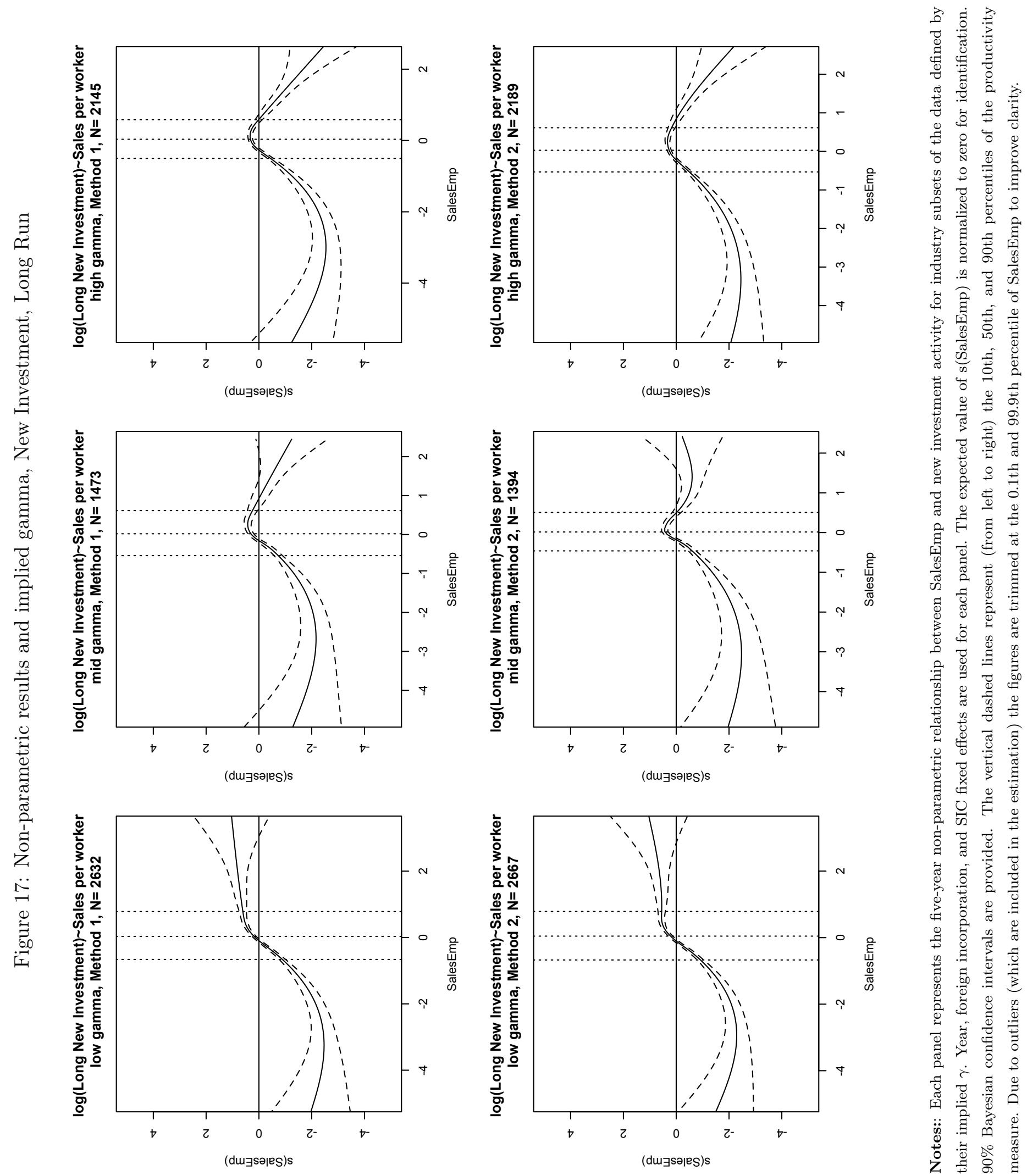

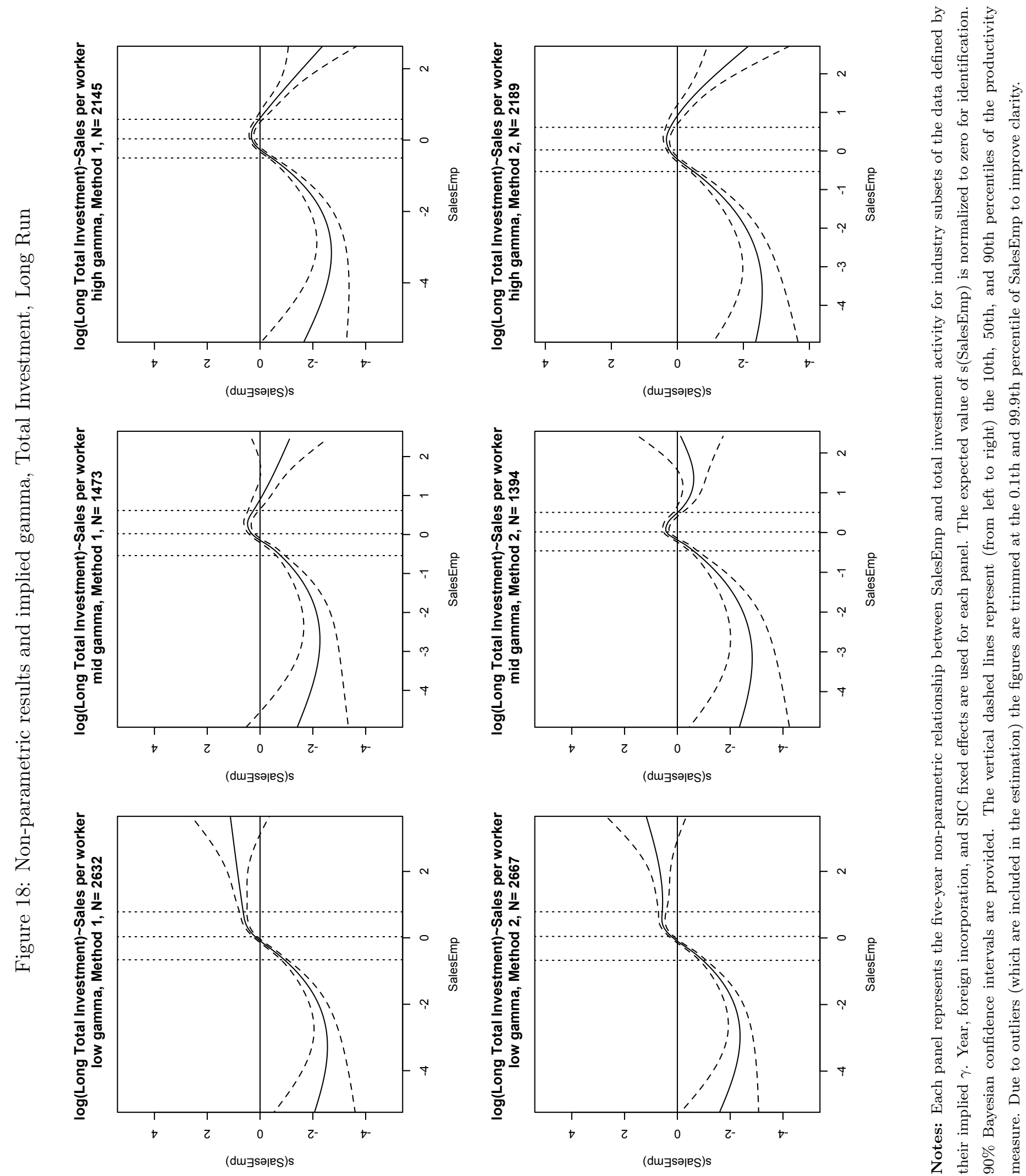

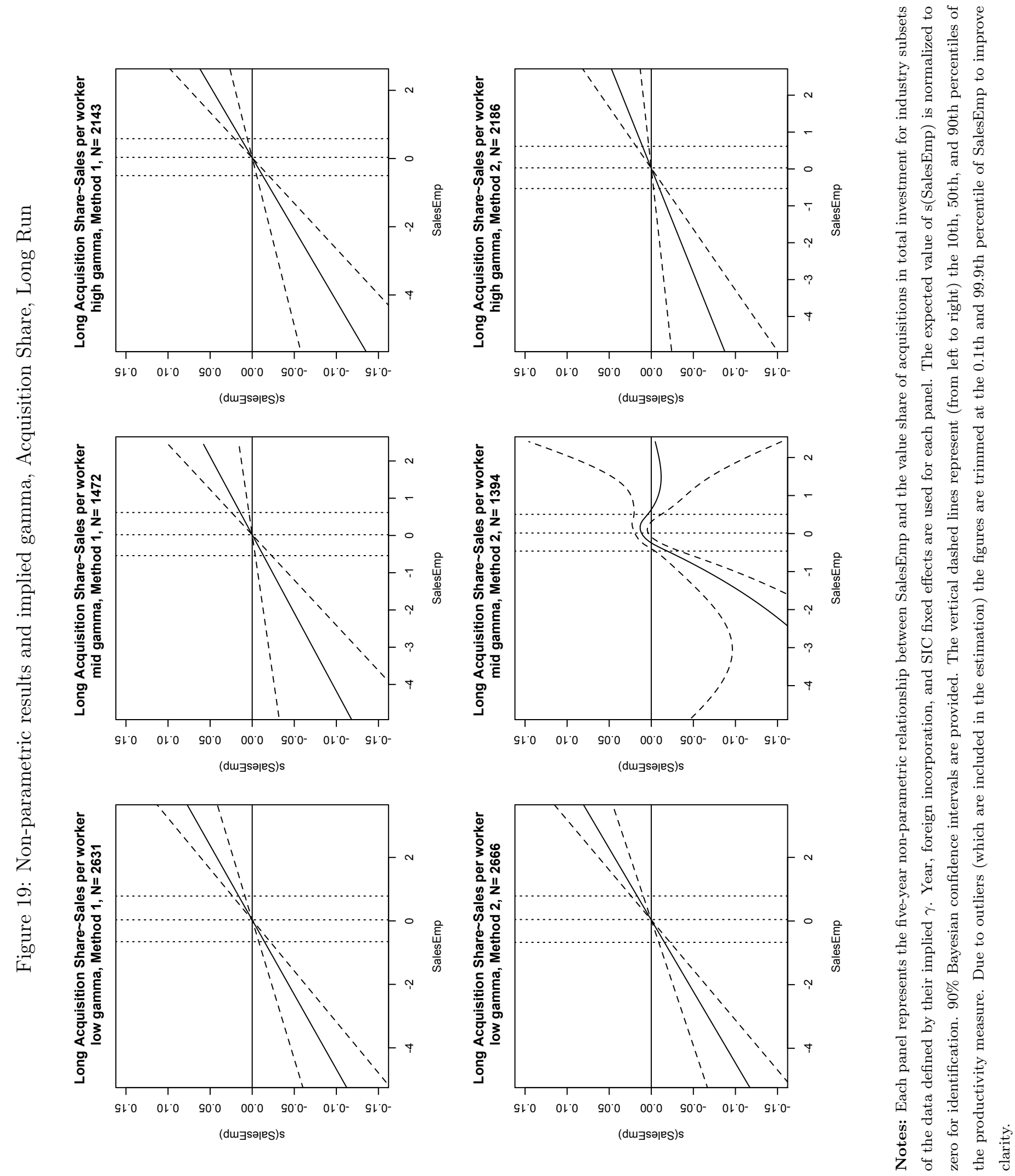